\title{
Long Non-Coding RNA SH3PXD2A-AS1 Promotes Cell Progression Partly Through Epigenetic Silencing P57 and KLF2 in Colorectal Cancer
}

\author{
Zhonghua Ma ${ }^{a, b}$ Peng Peng ${ }^{c}$ Jing Zhou ${ }^{a, b}$ Bingqing Huia ${ }^{a, b}$ Hao Ji $\mathrm{Ja}^{\mathrm{a}, \mathrm{b}}$ \\ Juan Wang ${ }^{b}$ Keming Wang ${ }^{a, b}$ \\ aThe Second Clinical Medical College of Nanjing Medical University, Nanjing, bepartment of Oncology, \\ Second Affiliated Hospital, Nanjing Medical University, Nanjing, 'Department of Oncology, Second \\ Hospital of Nanjing, Nanjing, P.R. China
}

\section{Key Words}

Long non-coding RNA • SH3PXD2A-AS1 • Cell cycle • Proliferation • Apoptosis • Colorectal cancer $\bullet$ P57 and KLF2

\begin{abstract}
Background/Aims: Colorectal cancer (CRC) is one of the most commonly diagnosed malignancies worldwide. Current evidence has revealed the key roles of long non-coding RNAs (IncRNAs) in multiple cancers, including CRC. In this study, we identified the IncRNA SH3PXD2A-AS1 as a novel molecule associated with CRC progression by analyzing the publicly available data from The Cancer Genome Atlas (TCGA) and Gene Expression Omnibus (GEO) datasets. Methods: Quantitative real-time polymerase chain reaction ( $\mathrm{QRT}$-PCR) assays were performed to examine the expression levels of SH3PXD2A-AS1 in CRC tissue samples and CRC cell lines. Cell viability examination, colony-formation experiments, ethynyl deoxyuridine (Edu) assays and flow cytometry were performed to investigate the roles of SH3PXD2A-AS1 in CRC proliferation, cell cycle regulation, and apoptosis. Transwell assays were used to explore the effects of SH3PXD2A-AS1 on CRC cells migration and invasion. A nude mice model was used to assess the effects of SH3PXD2A-AS1 on tumorigenesis in vivo. Subcellular fractionation, RNA immunoprecipitation (RIP), and chromatin immunoprecipitation (ChIP) assays were conducted to detect the molecular mechanisms of SH3PXD2A-AS1-mediated gene expression. Rescue assays were used to determine whether P57 and Kruppel-like factor 2 (KLF2) were involved in SH3PXD2A-AS1-dependent CRC proliferation. Results: We firstly found that SH3PXD2A-AS1 was significantly upregulated in CRC tissues and cell lines, and overexpression of SH3PXD2AAS1 was correlated with tumor size, TNM stage, and lymph node metastasis in patients with CRC. Furthermore, SH3PXD2A-AS1 knockdown inhibited CRC cells proliferation, migration and invasion in vitro, and suppressed tumorigenesis in vivo. Mechanistic studies indicated that
\end{abstract}

Z. Ma, P. Peng and J. Zhou contributed equally to this work

Keming Wang The Second Clinical Medical College of Nanjing Medical University,

Nanjing, 210000, Jiangsu (China)

E-Mail kemingwang@njmu.edu.cn 


\section{Cellular Physiology Cell Physiol Biochem 2018;46:2197-2214 and Biochemistry Published online: 1 May 01, $2018 \quad \begin{aligned} & \text { O 2018 The Authors. } \\ & \text { www.karger.com/cpb }\end{aligned}$

SH3PXD2A-AS1 could epigenetically repress P57 and KLF2 expression through interaction with EZH2. Rescue experiments suggested that SH3PXD2A-AS1-mediated oncogenesis was impaired by overexpression of P57 or KLF2. Interestingly, the expression of SH3PXD2A-AS1 was inversely correlated with the expression of P57 and KLF2 in CRC tissue samples. Conclusion: Our research presents the first evidence that SH3PXD2A-AS1 acts as an oncogene in CRC, and may be a promising diagnostic or therapeutic target in patients with CRC.

(C) 2018 The Author(s)

Published by S. Karger AG, Basel

\section{Introduction}

Colorectal cancer (CRC) is the third most commonly diagnosed malignancy worldwide [1-3]. In 2017, 71, 420 new cases of CRC and 27, 150 CRC-related deaths are expected to occur in the United States [1,2]. Importantly, progress in our understanding of CRC can be accelerated by elucidating the regulatory mechanisms involved in CRC carcinogenesis and development. Current evidence has highlighted the roles of long non-coding RNAs (lncRNAs) as crucial modulators in multiple types of tumors, including CRC [4-7]. Thus, novel insights into the involvement of IncRNAs are urgently needed.

LncRNAs are newly identified members of non-coding RNAs (ncRNAs), which exhibit limited or no protein-coding capacity [8]. Recently, dysregulation of IncRNAs has been reported to alter many biological processes, including cell cycle, proliferation, apoptosis, invasion, and epigenetic regulation [8-10]. Furthermore, IncRNAs are capable of exerting oncogenic or tumor-suppressive roles, and could be considered as diagnostic or therapeutic targets for patients with cancer [11-14]. Human CRC-specific IncRNA CCAT1-L enhances MYC expression and promotes tumorigenesis in CRC [15]. Dysregulated lncRNA-ATB is involved in CRC progression and correlates with clinicopathological factors in patients with CRC [16]. In addition, Sun et al. reported that lncRNA HOXA11-AS acts as an oncogene and promotes cell proliferation and invasion in gastric cancer (GC) [17]. Our previous study showed that overexpressed IncRNA FOXP4-AS1 is involved in CRC proliferation and predicts poor prognosis in patients with CRC [18]. Recent studies have shown that IncRNAs-mediated epigenetic repression of tumor suppressors is required for interaction with polycomb repressive complex 2 (PRC2) [19], thus promoting cancer progression [20-22]. Enhancer of zeste 2 (EZH2), SUZ12, and embryonic ectoderm development (EED), as critical components of PRC2, are closely related to carcinogenesis [23-25]. Hox transcript antisense intergenic RNA (HOTAIR) can interact with PRC2 to regulate target gene expression in multiple cancers, including CRC, GC, glioma, and oral squamous cell carcinoma [26-28]. Antisense ncRNA in the INK4 locus (ANRIL) can recruit SUZ12 to repress the expression of P15 ${ }^{\mathrm{INK} 4 \mathrm{~B}}$ locus [22]. LncRNA CRNDE interacts with EZH2 and repress DUSP5/CDKN1A expression in CRC [29]. According to our previous studies, IncRNA HOXA-AS2 promotes CRC progression partially via silencing P21 and Kruppel-like factor 2 (KLF2) expression through histone 3 lysine 27 trimethylation (H3K27me3) mediated by EZH2 [30]. However, the roles and molecular mechanisms of most lncRNAs remain largely unclear in cancer, particularly CRC. Thus, further studies are needed to identify and characterize novel lncRNAs.

In this study, SH3PXD2A-AS1 was screened out as a novel IncRNA associated with CRC through analyzing data from The Cancer Genome Atlas (TCGA) and Gene Expression Omnibus (GEO) datasets (GSE4183). SH3PXD2A-AS1 is an antisense transcript transcribed from SH3PXD2A and located on chromosome 10 with 2023 bp length. And SH3PXD2A has been identified to exert oncogenic roles in multiple cancers [31-34]. In this study, we found that dysregulation of SH3PXD2A-AS1 is correlated with clinicopathological factors in CRC patients. In vitro and in vivo assays revealed that SH3PXD2A-AS1 knockdown could suppress CRC cell progression and inhibit tumorigenesis. Mechanistic experiments showed that SH3PXD2A-AS1 can repress P57 and KLF2 expression through EZH2-mediated H3K27me3. Moreover, the oncogenic role of SH3PXD2A-AS1 can be impaired by overexpression of P57 or KLF2. Taken together, our findings suggested that SH3PXD2A-AS1 may be a candidate molecular biomarker for patients with CRC. 


\section{Cellular Physiology Cell Physiol Biochem 2018;46:2197-2214 \begin{tabular}{ll|l}
\cline { 2 - 2 } aOI: 10.1159/000489589 & $\begin{array}{l}\text { ( ) } 2018 \text { The Author(s). Published by S. Karger AG, Basel } \\
\text { www.karger.com/cpb }\end{array}$ \\
\hline
\end{tabular} Ma et al.: The Oncogenic Role of SH3PXD2A-AS1 in CRC Progression}

\section{Materials and Methods}

RNA sequencing and microarray data analysis

Colorectal cancer gene expression data were downloaded from the TCGA and GEO dataset. The BAM files and normalized probe-level intensity files were downloaded from TCGA and GEO databases, respectively. The probe sequences were downloaded from GEO or microarray manufacturers, and bowtie was used to reannotate probes according to GENCODE Release 19 annotation for IncRNAs. For multiple probes corresponding to one gene, the probe with the maximum signal was selected to generate expression of IncRNAs.

\section{Clinical specimens}

The clinical specimens were collected from 68 colorectal cancer patients, who accepted surgical operation at the Second Affiliated Hospital of Nanjing Medical University (China) between 2013 and 2017. All the patients signed the informed consents and did not accept any local or systemic treatment before surgery. All collected tissue samples were immediately snap-frozen in liquid nitrogen and stored at $-80^{\circ} \mathrm{C}$ until required. All the research conforms to the rules and regulations of the Research Ethics Committee of Nanjing Medical University (Nanjing, Jiangsu, PR China).

\section{Cell culture}

Four CRC cell lines (SW480, DLD-1, HT-29, and LOVO) and the human colonic epithelial cells HCoEpiC were purchased from American Type Culture Collection (Manassas, VA, USA). All cell lines were maintained in Dulbecco's modified Eagle's medium (DMEM; Invitrogen, Shanghai, China) in humidified air at $37^{\circ} \mathrm{C}$ with $5 \%$ CO2. All media were supplemented with $10 \%$ fetal bovine serum (10\% FBS), $100 \mathrm{U} / \mathrm{ml}$ penicillin and $100 \mathrm{mg} / \mathrm{ml}$ streptomycin (Invitrogen).

\section{RNA isolation and $q R T-P C R$}

For tissue samples, a precooled mortar and pestle was used to grind the frozen tissue under liquid nitrogen. TRIzol reagent (Invitrogen, Carlsbad, CA) was added to dissolve tissues and cells as soon as possible to prepare total RNA. NanoDrop2000c (Thermo Scientific, Waltham, MA, USA) works to determine the RNA concentration and quality. For qRT-PCR assays, cDNA was synthesized from $1 \mu \mathrm{g}$ of total RNA using a Reverse Transcription Kit (Takara, Dalian, China). The quantitative polymerase chain reaction (qPCR) assays were performed using an ABI 7500 system. GAPDH was used as a control. Primers used for target amplification are listed in Table 2.

\section{Cell transfection}

Lipofectamine 2000 (Invitrogen, USA) was used to transfect siRNA into cells. Plasmid vectors (shSH3PXD2A-AS1 and empty vector) for transfection were extracted by DNA Midiprep kit (Qiagen, Hilden, Germany) and transfected into cells using Fugene (Roche, USA). The sequences of the siRNAs and shRNAs are described in Table 2. Cells were harvested after 48 $\mathrm{h}$ for qRT-PCR and Western blot analyses. The P57 and KLF2 sequence were respectively synthesized and subcloned into the pcDNA3.1 vector (GENECHEM, Shanghai, China) to generate the pcDNA-P57 vector and pcDNA-KLF2 vector for ectopic expression in cells. pcDNA3.1 vector was used as a control.

Table 1. Relationship between SH3PXD2A-AS1 expression and clinicopathological characteristics of CRC patients

\begin{tabular}{|c|c|c|c|}
\hline Characteristics & SH3PXD2A-AS1 & SH3PXD2A-AS1 & $\mathrm{P}$ \\
\hline & $\begin{array}{c}\text { Low no. case }(\%) \\
(\mathrm{n}=34)\end{array}$ & $\begin{array}{r}\text { High no. case ( } \\
(\mathrm{n}=34)\end{array}$ & $\begin{array}{l}\text { squared test } \\
\text { P-value }\end{array}$ \\
\hline \multicolumn{4}{|l|}{ Age(years) } \\
\hline$\leq 60$ & $17(50.0)$ & $13(38.2)$ & \multirow[t]{2}{*}{0.329} \\
\hline$>60$ & $17(50.0)$ & $21(61.8)$ & \\
\hline \multicolumn{4}{|l|}{ Gender } \\
\hline Male & $12(35.3)$ & $14(41.2)$ & \multirow[t]{2}{*}{0.618} \\
\hline Female & $22(64.7)$ & $20(58.8)$ & \\
\hline \multicolumn{4}{|l|}{ Location } \\
\hline Colon & $24(70.6)$ & $18(53.0)$ & \multirow[t]{2}{*}{0.134} \\
\hline Rectum & $10(29.4)$ & $16(47.0)$ & \\
\hline \multicolumn{4}{|l|}{ Tumor size } \\
\hline$\leq 5 \mathrm{~cm}$ & $18(53.0)$ & $5(15.0)$ & \multirow[t]{2}{*}{$0.001^{*}$} \\
\hline$>5 \mathrm{~cm}$ & $16(47.0)$ & $29(85.0)$ & \\
\hline \multicolumn{4}{|l|}{ TNM Stage } \\
\hline I/II & $20(58.8)$ & $8(23.5)$ & \multirow{3}{*}{$0.003^{*}$} \\
\hline III/IV & $14(41.2)$ & $26(76.5)$ & \\
\hline \multicolumn{3}{|c|}{ Lymph node metastasis } & \\
\hline Positive & $14(41.2)$ & $26(76.5)$ & \multirow[t]{3}{*}{$0.003^{*}$} \\
\hline Negative & $20(58.8)$ & $8(23.5)$ & \\
\hline$* \mathrm{P}<0.05$ & & & \\
\hline
\end{tabular}




\section{Cellular Physiology Cell Physiol Biochem 2018;46:2197-2214 \begin{tabular}{l|l} 
and Biochemistry Publisned onlIne: IVlay 07, 2018 & $\begin{array}{l}\text { () 2018 The Author(s). Published by S. Karger AG, Basel } \\
\text { www.karger.com/cpb }\end{array}$
\end{tabular} \\ Ma et al.: The Oncogenic Role of SH3PXD2A-AS1 in CRC Progression}

Table 2. qRT-PCR primers and sequences of siRNAs and shRNAs

\begin{tabular}{|c|c|c|}
\hline \multicolumn{3}{|l|}{ qRT-PCR primers } \\
\hline Gene & Forward & Reverse \\
\hline SH3PXD2A-AS1 & GCCTCTTTACAGCGTTCCCT & CCTGAGGATACGTTCGTGGG \\
\hline GAPDH & GAAGAGAGAGACCCTCACGCTG & ACTGTGAGGAGGGGAGATTCAGT \\
\hline P15 & ACGGAGTCAACCGTTTCGGGAG & GGTCGGGTGAGAGTGGCAGG \\
\hline P16 & ATGGAGCCTTCGGCTGACT & GGCCTCCGACCGTAACTATT \\
\hline P21 & CAGCAGAGGAAGACCATGTG & GGCGTTTGGAGTGGTAGAAA \\
\hline P27 & TGCAACCGACGATTCTTCTACTCAA & CAAGCAGTGATGTATCTGATAAACAAGG \\
\hline P57 & CACGATGGAGCGTCTTGTC & CCTGCTGGAAGTCGTAATCC \\
\hline KLF2 & TTCGGTCTCTTCGACGACG & TGCGAACTCTTGGTGTAGGTC \\
\hline PTEN & AGTTCCCTCAGCCGTTACCT & AGGTTTCCTCTGGTCCTGGT \\
\hline EZH2 & TGCACATCCTGACTTCTGTG & AAGGGCATTCACCAACTCC \\
\hline \multirow{2}{*}{\multicolumn{3}{|c|}{ AACGCTTCACGAATTTGCGT }} \\
\hline & & \\
\hline SH3PXD2A-AS1 1\# & CCACCAUUGAUAAUGAUCUUCUGAA & UUCAGAAGAUCAUUAUCAAUGGUGG \\
\hline SH3PXD2A-AS1 2\# & CACACAAAUCACCUGUGCAUGUUAA & UUAACAUGCACAGGUGAUUUGUGUG \\
\hline SH3PXD2A-AS1 3\# & GAUGGAGCUUCAGAAUUAAACUGAU & \\
\hline si-EZH2 1\# & GAGGUUCAGACGAGCUGAUUU & \\
\hline si-EZH2 2\# & GCUCCUCUAACCAUGUUUATT & \\
\hline \multicolumn{3}{|l|}{ sh-RNAs } \\
\hline SH3PXD2A-AS1 2\# & CACCGCACACAAATCACCTGTGCATGTTAACGAATTAACATGCACAGGTGATTTGTGTG & AAAACACACAAATCACCTGTGCATGTTAATTCGTTAACATGCACAGGTGATTTGTGTGC \\
\hline SH3PXD2A-AS1 3\# & CACCGATGGAGCTTCAGAATTAAACTGATCGAAATCAGTTTAATTCTGAAGCTCCATC & AAAAGATGGAGCTTCAGAATTAAACTGATTTCGATCAGTTTAATTCTGAAGCTCCATC \\
\hline EZH2 & CACCGCAACACCCAACACTTATAAGTTCAAGAGACTTATAAGTGTTGGGTGTTGCTTTTTTG & GATCCAAAAAAGCAACACCCAACACTTATAAGTCTCTTGAACTTATAAGTGTTGGGTGTTGC \\
\hline
\end{tabular}

Cell proliferation and apoptosis analysis

Cell Proliferation Reagent Kit I (MTT) (Roche Applied Science) and EdU assay kit (Life Technologies Corporation Carlsbad, CA, USA) were used to test cell viability. Flow cytometric examination was conducted to the alteration of cell cycle and apoptosis. The cells were stained with PI using the CycleTESTTM PLUS DNA Reagent Kit (BD Biosciences) and analyzed with a flow cytometer (FACScan®; BDBiosciences) equipped with the CellQuest software (BD Biosciences). The percentages of the cells in G0-G1, S, and G2-M phases were calculated and compared. For apoptosis analysis, the cells were then treated with fluorescein isothiocyanate (FITC) Annexin V and propidium iodide (PI) in the dark at room temperature. Subsequently, the cells were analyzed by FACScan ${ }^{\circledR}$, and they were identified as viable, dead, early apoptotic, or late apoptotic cells.

\section{Western blot assay}

The cells were lysed using the mammalian protein extraction reagent, RIPA (Beyotime, Shanghai, China), supplemented with a protease inhibitor cocktail (Roche) and PMSF (Roche). Protein were separated by $10 \%$ sodium dodecyl sulfate-polyacrylamide gel electrophoresis (SDS-PAGE), transferred to $0.22 \mathrm{~mm}$ nitrocellulose membranes (Sigma) and incubated with specific primary antihuman antibodies. The secondary antibody was horseradish peroxidase-conjugated goat anti-rabbit IgG. An ECL chromogenic substrate was used to visualize the bands and the intensity of the bands was quantified by densitometry (Quantity One software; Bio-Rad, Hercules, CA, USA). A GAPDH (\#2118, CST, USA) antibody was used as a control. The anti-CDK2 (\#2546, CST, USA), anti-CDK4 (\#12790, CST, USA), anti-CDK6 (\#13331,CST,USA), and anti-Cyclin D1 (\#2978, CST, USA) (all 1:1000) antibodies were purchased from Cell Signaling Technology, Inc. (CST). The anti-P57 (SAB5500158, Sigma) and anti-KLF2 (SAB1101046, Sigma) antibodies were purchased from Sigma.

\section{Subcellular fractionation location}

The separation of nuclear and cytosolic fractions was performed using the PARIS Kit (Life Technologies) according to the manufacturer's instructions.

\section{RNA immunoprecipitation (RIP)}

RNA immunoprecipitation was used to investigate whether SH3PXD2A-AS1 could bind with the potential binding protein (EZH2 and SUZ12). We used the EZMagna RIP kit (Millipore, Billerica, MA, USA) following the manufacturer's protocol. Cells were lysed in complete RIP lysis buffer, and the extract was incubated with magnetic beads conjugated with antibodies that recognized EZH2, SUZ12, or control IgG (millipore) for $6 \mathrm{~h}$ at $4^{\circ} \mathrm{C}$. Then, the beads were washed and incubated with Proteinase $\mathrm{K}$ to remove proteins. Finally, purified RNA was subjected to qPCR analysis to demonstrate the presence of SH3PXD2A-AS1 using specific primers.

\section{Chromatin immunoprecipitation (ChIP)}

Cells were treated with formaldehyde and incubated for 10 mins to generate DNA-protein cross-links. Cell lysates were then sonicated to generate chromatin fragments of 200-300 bp and immunoprecipitated with EZH2 and H3K27me3-specific antibody (Millipore) or IgG as control. Precipitated 


\section{Cellular Physiology Cell Physiol Biochem 2018;46:2197-2214

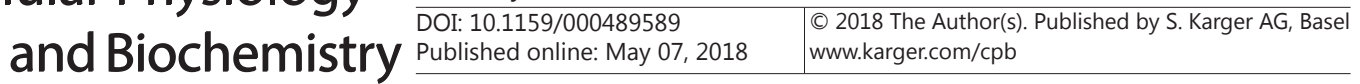 \\ Ma et al.: The Oncogenic Role of SH3PXD2A-AS1 in CRC Progression}

chromatin DNA was recovered and analyzed by qRT-PCR. ChIP-qRT-PCR primers for P57 are as follows: $5^{\prime}$-GGTGTCTAGGTGCTCCAGGT-3'(sense), $5^{\prime}$-GCACTCTCC AGGAGGACACA-3'(antisense). ChIP qPCR primers for KLF2 are as follows: $5^{\prime}$-ACGGGCTTATTGAGGTTGG-3'(sense), 5'-GCCTGGGTGACAGAGGAGAC$3^{\prime}$ (antisense).

\section{In-vivo tumor model}

Four-week-old male athymic mice were provided from the Animal Center of the Nanjing University (Nanjing, China). The feeding environment is pathogen-free. DLD-1 cells were transfected with shSH3PXD2A-AS1 or empty vector and harvested from six-well plates, washed with phosphate-buffered saline (PBS), and resuspended at $2 \times 10^{7}$ cells $/ \mathrm{mL}$. Subsequently, each mouse was injected into the lower right flank with $100 \mu \mathrm{L}$ of suspended cells. Tumor growth was examined every 4 days, and tumor volumes were calculated using the quation $\mathrm{V}=0.5 \times \mathrm{D} \times \mathrm{d}^{2}(\mathrm{~V}$, volume; $\mathrm{D}$, longitudinal diameter; $\mathrm{d}$, latitudinal diameter $)$.

Fig. 1. Relative SH3PXD2A-AS1 expression in CRC tissues. A-B. Hierarchical clustering analysis of IncRNAs that were differentially expressed (fold change $>2 ; \quad \mathrm{P}<0.05$ ) in colorectal cancer and normal tissues. C. Relative expression of misregulated IncRNAs in TCGA data and GEO datasets (GSE4183). D. Higher SH3PXD2A-AS1 expression levels in the profiles of colorectal tissue samples from TCGA and GEO datasets (GSE4183). E. Relative expression levels of SH3PXD2AAS1 in CRC tissues $(n=68)$ compared with matched non-tumor tissues ( $n=68)$, and the patients were divided into high SH3PXD2AAS1 expression group ( $\mathrm{n}=34$, > median value ) and low SH3PXD2AAS1 expression group ( $\mathrm{n}=34,<$ median value) according to the median value of SH3PXD2A-AS1 expression levels.

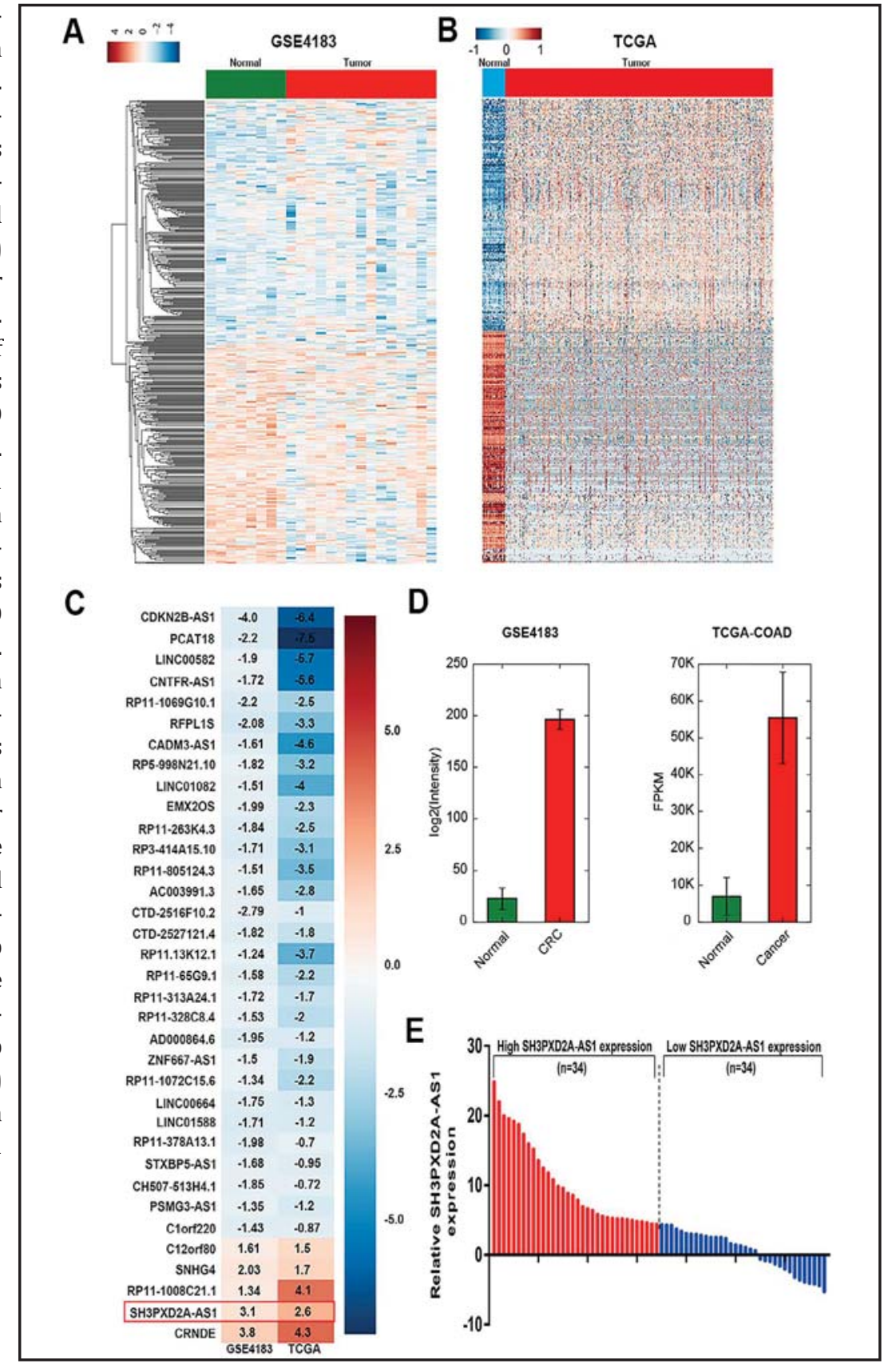




\section{Cellular Physiology Cell Physiol Biochem 2018;46:2197-2214 \begin{tabular}{ll|l}
\cline { 2 - 2 } aOI: 10.1159/000489589 & $\begin{array}{l}\text { ( ) } 2018 \text { The Author(s). Published by S. Karger AG, Basel } \\
\text { www.karger.com/cpb }\end{array}$ \\
\hline
\end{tabular} \\ Ma et al:: The Oncogenic Role of SH3PXD2A-AS1 in CRC Progression}

At 24 days post-injection, mice were sacrificed by $\mathrm{CO} 2$ asphyxiation, and the growth of each tumor was examined. The wet weight of each tumor was detected using electric balance. The protocol was approved by the Committee on the Ethics of Animal Experiments of the Nanjing Medical University.

\section{Immunohistochemistry (IHC)}

Xenograft tumor tissue samples were immunostained for H \& E and Ki67. Anti-Ki67 was from Santa Cruz Biotechnology (Dallas, TX, USA). The IHC staining results were independently scored by the author and a pathologist to minimize subjectivity and then compared, and the final comprehensive results were obtained.

\section{Statistical analysis}

Chi-square test was used to analyze the correlation between SH3PXD2A-AS1 expression and clinicopathological features in CRC patients. Statistical analysis was then performed using Student's t-test (two-sided) between two groups or Analysis of Variance (ANOVA) followed by Bonferroni post test for comparsions among multiple groups. If the results were not normally distributed, Mann-Whitney U test and Wilcoxon test were used as appropriate. Statistical analysis was performed using SPSS software, version 22.0 (SPSS, Chicago, IL, USA) . Error bars indicate mean \pm s.d (standard deviation) in three independent experiments. ${ }^{*} \mathrm{P}<0.05,{ }^{* *} \mathrm{P}<0.01$.

\section{Results}

SH3PXD2A-AS1 expression was increased in CRC tissues and correlated with tumor size, TNM stage, and lymph node metastasis in patients with CRC

To identify novel oncogenic IncRNAs involved in CRC progression, publicly available data from GEO (GSE4183) and TCGA datasets were analyzed to find aberrantly expressed lncRNAs (Fig. 1A-1B). We focused on overexpressed IncRNAs showing fold changes of more than 2 in both GSE4183 and TCGA datasets, and two novel lncRNAs, SH3PXD2A-AS1 and CRNDE, were identified (Fig. 1C). Because several research groups are already studying the role of CRNDE in carcinogenesis, including CRC progression, in this study, we decided to focus on SH3PXD2A-AS1, which was obviously upregulated in both GSE4183 and TCGA datasets (Fig. 1D). First, qRT-PCR assays were performed to validate SH3PXD2A-AS1 expression in 68 CRC tissues and corresponding non-tumor samples, and showed that SH3PXD2A-AS1 was significantly increased in CRC tissues compared with adjacent non-tumor tissues.

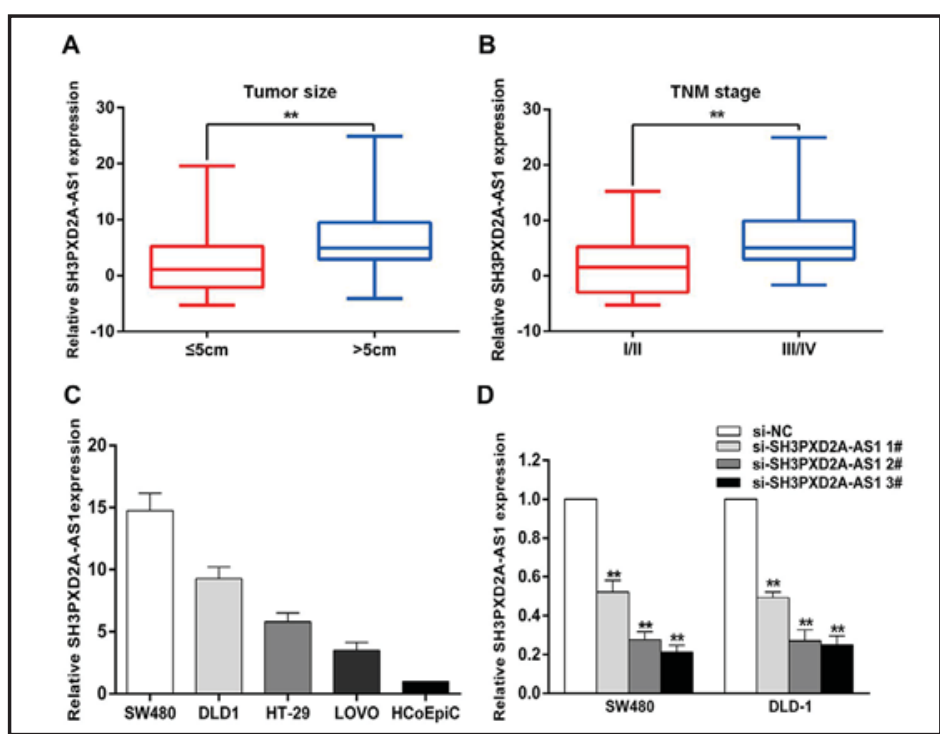

Fig. 2. SH3PXD2A-AS1 exhibited significant correlation with clinicopathological factors of CRC patients, and its expression levels in CRC cell lines. A-B. Increased SH3PXD2A-AS1 expression was obviously associated with tumor size, TNM stage, and lymph node metastasis in CRC patients. C. The expression levels of SH3PXD2A-AS1 in CRC cell lines and normal colonic epithelial cells. D. qRT-PCR analysis of SH3PXD2A-AS1 expression levels in SW480 and DLD-1 transfected with SH3PXD2A-AS1 siRNAs. Values are shown as the mean \pm s.d in three independent experiments. ${ }^{*} \mathrm{P}<0.05,{ }^{* *} \mathrm{P}<0.01$. 


\section{Cellular Physiology Cell Physiol Biochem 2018;46:2197-2214 \begin{tabular}{l|l|l|}
\hline DOI: 10.1159/000489589 & 02018 The Author(s). Published by S. Karger AG, Basel \\
\hline
\end{tabular} and Biochemistry Published online: May 07, 2018 www.karger.com/cpb}

Fig. 3. SH3PXD2A-AS1 promotes CRC cell proliferation in vitro. A. Decreased SH3PXD2A-AS1 expression inhibited cell viability in SW480 and DLD-1 cell lines. B. Colony formation assays were performed to determine the proliferative capacities of sh-SH3PXD2A-AS1-transfected SW480 and DLD-1 cells. The colonies were counted and captured. C. Proliferating SW480 and DLD-1 cells were labeled with Edu. The Click-it reaction revealed Edu staining (red). Cell nuclei were stained with DAPI (blue). Values are shown as the mean \pm s.d in three independent experiments. ${ }^{*} \mathrm{P}<0.05,{ }^{* *} \mathrm{P}<0.01$.

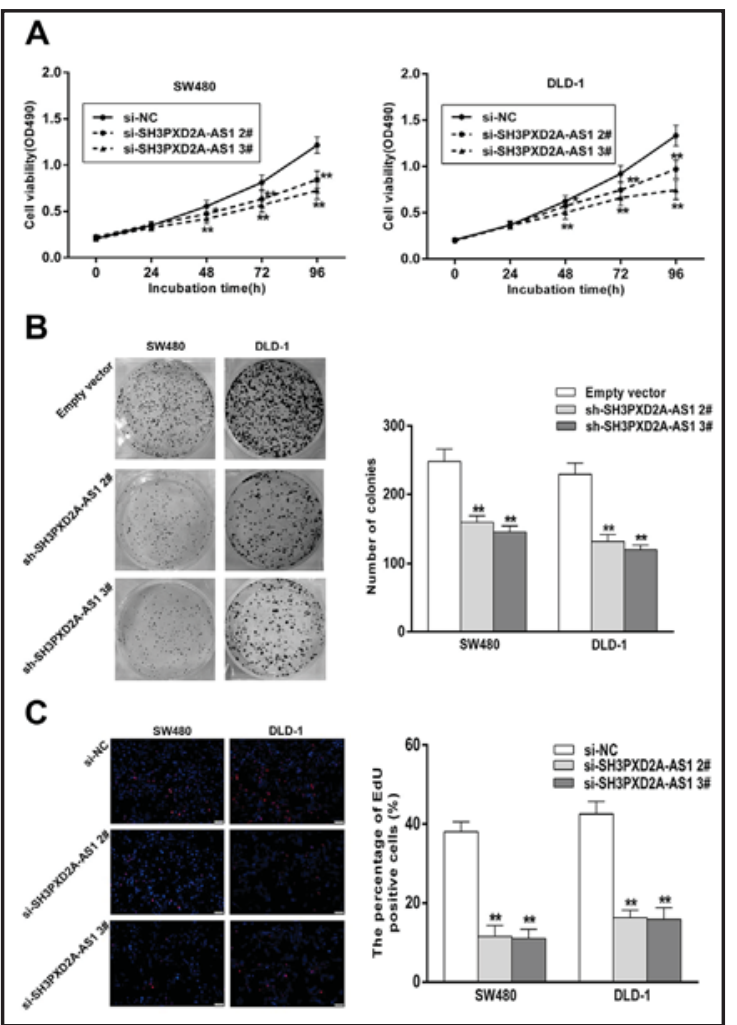

Fig. 4. SH3PXD2A-

AS1 regulates cell cycle and apoptosis in CRC cells. A. Knockdown of SH3PXD2AAS1 could promote G1/G0 phase arrest in SW480 and DLD- 1 cell lines. B. SH3PXD2AAS1 downregulation could increase apoptotic rates in SW480 and DLD-1 cell lines. C. Western blot assays were performed to detect cyclinD1, CDK2, CDK4, and CDK6 protein levels in SW480 and DLD1 cells transfected with SH3PXD2A-AS1 siRNAs. Values are shown as the mean \pm s.d in three independent experiments. ${ }^{*} \mathrm{P}<0.05,{ }^{* *} \mathrm{P}<0.01$.

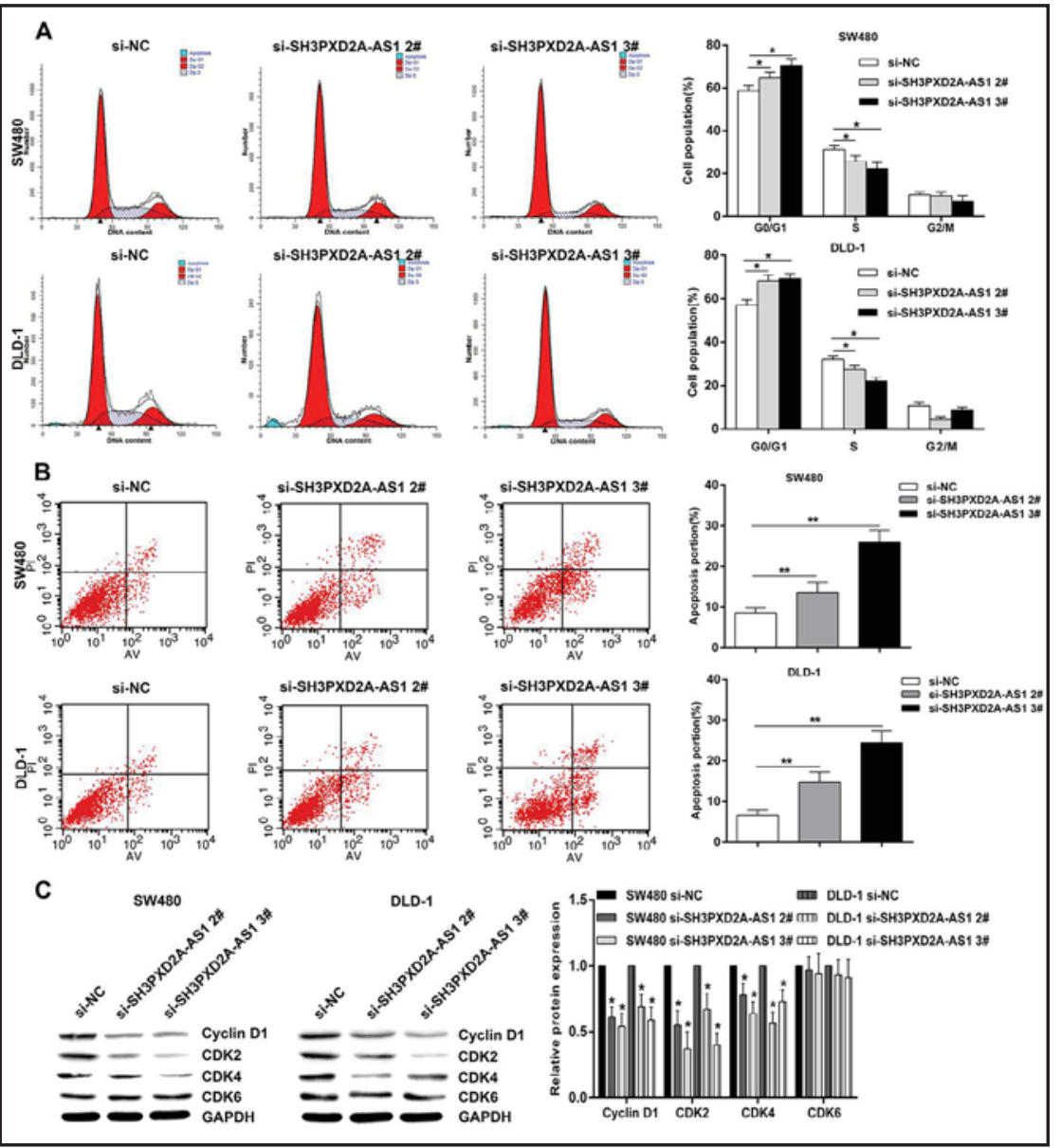




\section{Cellular Physiology Cell Physiol Biochem 2018:46:2197-2214

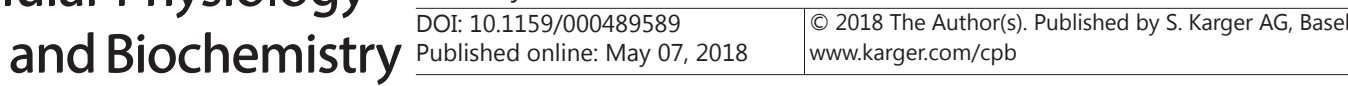 \\ Ma et al.: The Oncogenic Role of SH3PXD2A-AS1 in CRC Progression}

Fig. 5. Decreased SH3PXD2A-AS1 expression could suppress tumor growth in vivo. A. The size of tumor derived from sh-SH 3 PXD 2 A-AS1transfected DLD-1 cells was obviously smaller than that derived from empty-vector-transfected DLD-1 cells. B. The expression of SH3PXD2A-AS1 was significantly decreased

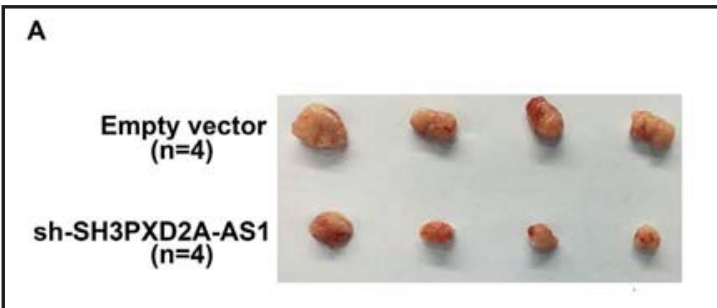

C

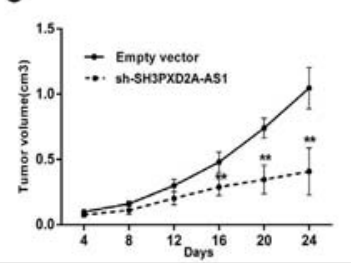

D

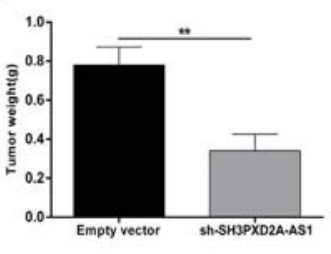

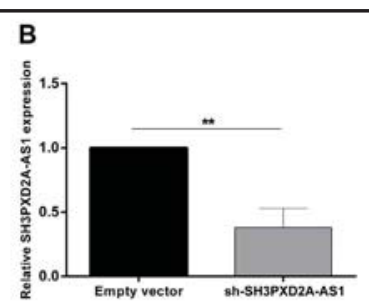

E

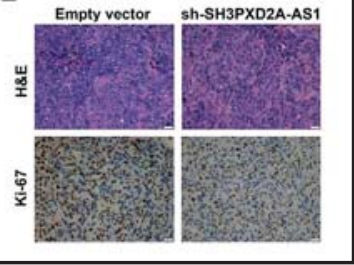
in tumors formed from sh-SH3PXD2A-AS1-transfected DLD-1 cells. C. Tumor volumes in sh-SH3PXD2A-AS1 group and empty vector group were examined every 4 days. D. The weight of tumor in sh-SH3PXD2A-AS1 group was remarkably lighter than that in empty-vector group. E. Tumor formed from sh-SH3PXD2A-AS1 group exhibited lower ki-67 expression, compared with that from empty vector group. Values are shown as the mean \pm s.d in three independent experiments. ${ }^{*} \mathrm{P}<0.05,{ }^{*} \mathrm{P}<0.01$.

Based on the expression levels of SH3PXD2A-AS1 in CRC, we divided 68 CRC into high ( $\mathrm{n}=34$, $>$ median value) and low ( $n=34,<$ median value) SH3PXD2A-AS1 expression groups to better study the relationships between SH3PXD2A-AS1 expression and clinicopathological features of CRC patients (Fig. 1E). Our findings showed that SH3PXD2A-AS1 was obviously associated with tumor size $(p=0.001)$, TNM stage $(p=0.003)$, and lymph node metastasis $(p=0.003)$ in patients with CRC (Fig. 2A-2B), whereas no significant correlations were found in other factors, such as age, gender, and location (Table 1).

\section{Regulation of SH3PXD2A-AS1 expression in CRC cell lines}

To detect the functional effects of SH3PXD2A-AS1 in CRC cells, we examined the expression levels of SH3PXD2A-AS1 in SW480, DLD-1, HT29, LOVO and HCoEpiC cells using qRT-PCR assays (Fig. 2C) and then altered SH3PXD2A-AS1 expression in CRC cell lines. The results showed that SH3PXD2A-AS1 expression was obviously decreased in SW480 and DLD1 cells transfected with SH3PXD2A-AS1 siRNAs, and si-SH3PXD2A-AS1 2\# and si-SH3PXD2AAS1 3\# showed higher RNA interference capacities (Fig. 2D). Furthermore, SH3PXD2A-AS1 expression was significantly upregulated in LOVO cells transfected with pcDNA-SH3PXD2AAS1 as compared with control cells (Fig. 9A). Thus, si-SH3PXD2A-AS1 2\#, si-SH3PXD2A-AS1 3\#, empty vector, and pcDNA-SH3PXD2A-AS1 were used in subsequent studies.

\section{Effects of SH3PXD2A-AS1 on CRC cell proliferation}

Next, we performed loss-of-function and gain-of-function assays in CRC cells. MTT assays showed that SH3PXD2A-AS1 knockdown decreased cell viability in SW480 and DLD-1 cells (Fig. 3A). Consistent with these findings, colony formation and EdU assays also revealed that decreased SH3PXD2A-AS1 expression inhibited the proliferative capacities of SW480 and DLD-1 cells (Fig. 3B, 3C). Moreover, SH3PXD2A-AS1 overexpression exhibited opposite effects (Fig. 9B, 9C).

SH3PXD2A-AS1 regulated cell cycle progression, migration, and invasion and suppressed apoptosis in $C R C$

Next, we investigated the functional role of SH3PXD2A-AS1 in the regulation of cell cycle and apoptosis. Flow cytometry assays were conducted to investigate the alterations of cell cycle and apoptosis in SW480 and DLD-1 cells with SH3PXD2A-AS1 knockdown, compared 


\section{Cellular Physiology Cell Physiol Biochem 2018;46:2197-2214

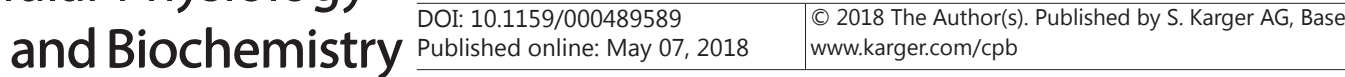 \\ Ma et al.: The Oncogenic Role of SH3PXD2A-AS1 in CRC Progression}

Fig. 6. SH3PXD2A-AS1 is mainly distributed in the nucleus and interacts with PRC2 in CRC cell lines. A. Relative expression of EZH2 in human CRC tissues $(n=50)$ compared with corresponding adjacent normal tissues $(n=50)$. EZH2 expression was examined by qPCR and normalized to GAPDH expression (shown as $\Delta \mathrm{CT})$. B. The expression levels of EZH2 in SW480, DLD-1, and normal colonic epithelial cells. C. qRT-PCR assays were conducted to test EZH2 expression levels in SW480 and DLD-1 cells with EZH2 siRNAs. D. SH3PXD2A-AS1 in nucleus was obviously higher than the portion of SH3PXD2AAS1 in cytoplasm. U6 was used as a nucleus marker, and GAPDH was used as a cytosol marker. E. SH3PXD2A-AS1 RNA levels in immunoprecipitates were determined by qRTPCR. Expression levels of SH3PXD2A-AS1 RNA were presented as fold enrichment relative to IgG immunoprecipitates.
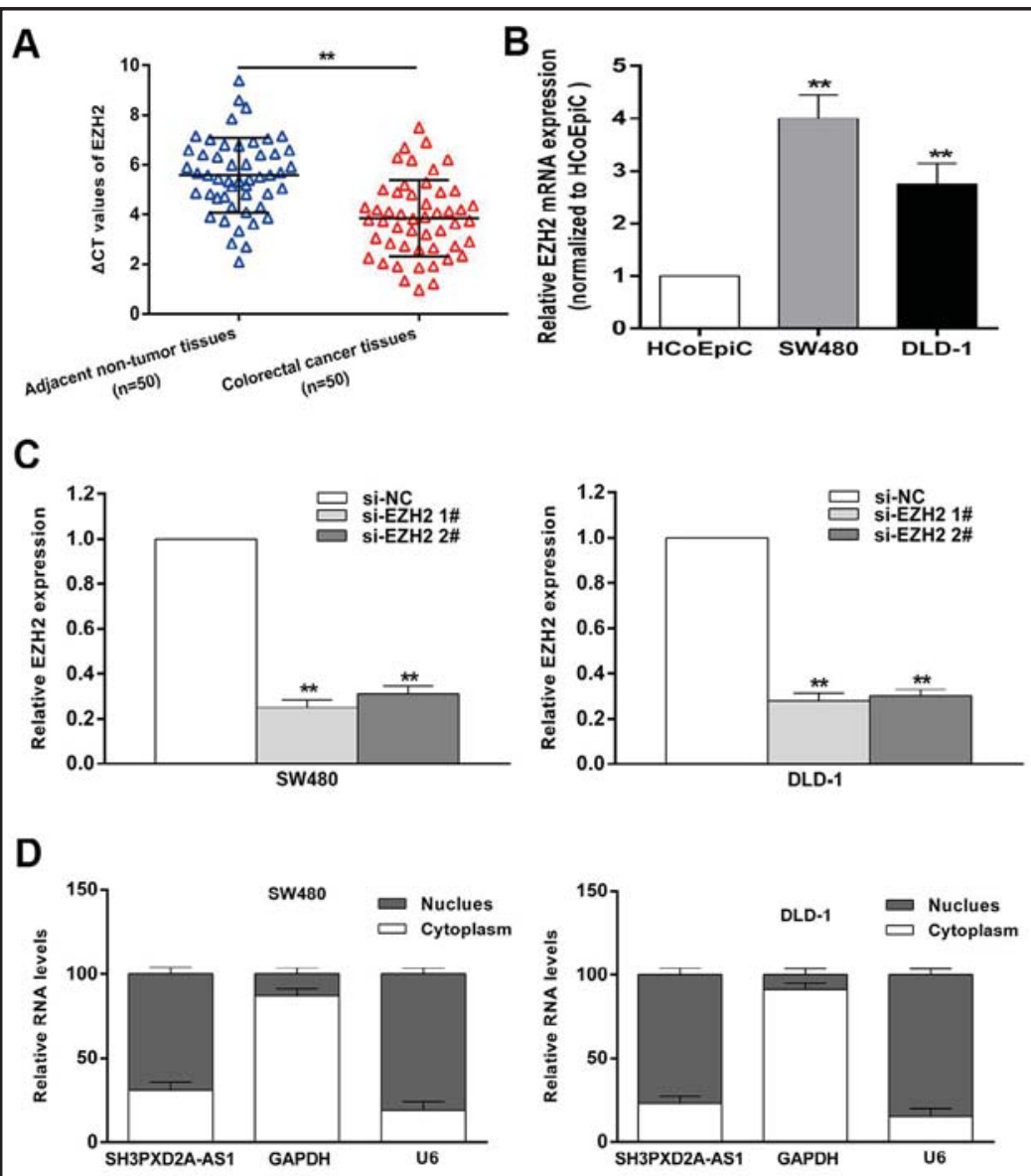

E
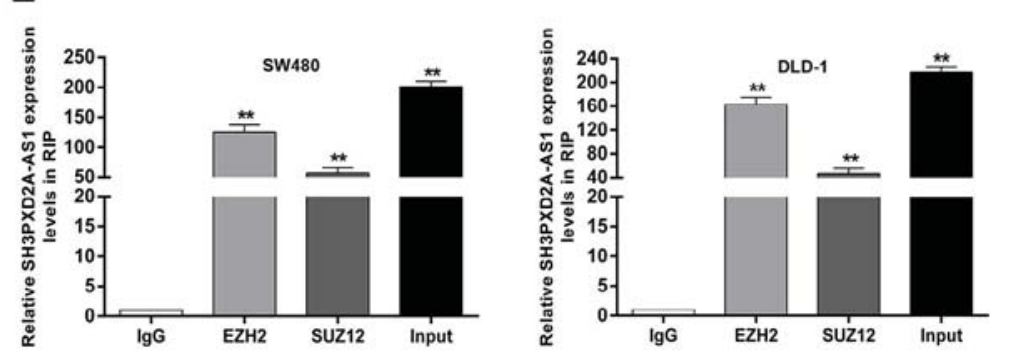

with respective controls. The results showed that SW480 and DLD-1 cells transfected with SH3PXD2A-AS1 2\# or 3\# exhibited obvious increase in G1/G0 phase and marked decrease in G2/S phase (Fig. 4A). Furthermore, the apoptotic rates were significantly upregulated in SW480 and DLD-1 cells transfected with SH3PXD2A-AS1 2\# or 3\# (Fig. 4B). We then examined the protein level of cell-cycle-related modulators, and found remarkable alteration of cyclin D1, cyclin-dependent kinase (CDK) 2, and CDK 4 in CRC cells with SH3PXD2A-AS1 knockdown as compared with control cells (Fig. 4C).

As our findings showed that SH3PXD2A-AS1 knockdown promoted G1/G0 phase arrest, and activated apoptosis in CRC cells, we studied whether SH3PXD2A-AS1 exerted critical roles in CRC migration and invasion through Transwell assays. The data demonstrated that SH3PXD2A-AS1 downregulation significantly inhibited cell migration and invasion (Fig. $10 \mathrm{~A})$. 

Cellular Physiology Cell Physiol Biochem 2018;46:2197-2214 \begin{tabular}{l|l|l}
\hline DOI: 10.1159/000489589 & 2018 The Author(s). Published by S. Karger AG, Basel \\
\hline
\end{tabular} Published online: May 07, 2018 www.karger.com/cpb

Fig. 7. SH3PXD2AAS1 could silence P57 and KLF2 expression through EZH2-mediated H3K27me3.A-B. The expression levels of P15, P16, P21, P27, P57, PTEN, and KLF2 were evaluated in SW480 and DLD-1 cells transfected with si-SH3PXD2A-AS1 2\# or $3 \#$ using qRT-PCR and western blot assays. * $\mathrm{P}<0.05$ and ${ }^{* *}$ $\mathrm{P}<0.01$. C. qRT-PCR assays were used to test the expression levels of P57 and KLF2 in SW480 and DLD-1 with EZH2 knockdown. D. ChIP-qRT-PCR of EZH2 occupancy and H3K$27 \mathrm{me} 3$ binding in the P57 and KLF2 promoters in SW480 and DLD1 cells treated with si-SH3PXD2A-AS1 3\# (48 h) or si-NC; IgG as a negative control. Values are shown as the mean \pm s.d in three independent experiments. ${ }^{*} \mathrm{P}<0.05,{ }^{* *} \mathrm{P}<0.01$.
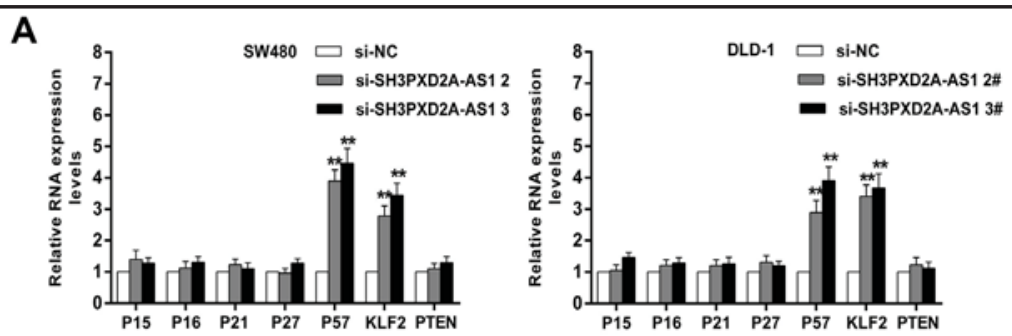

B
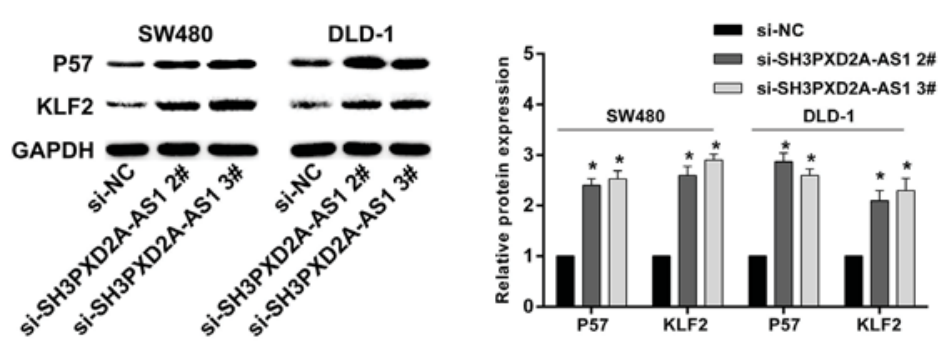

C
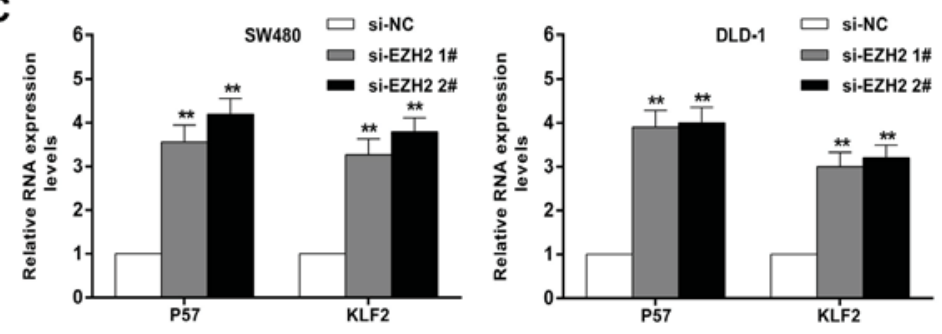

D

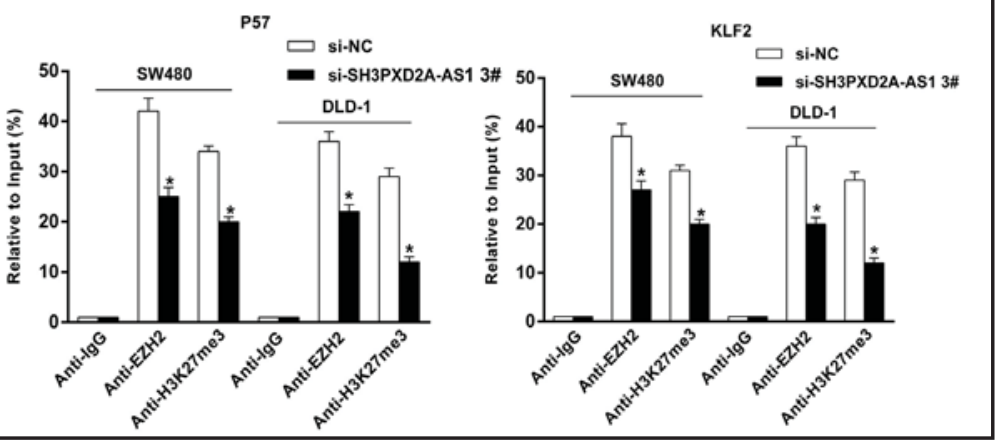

Downregulation of SH3PXD2A-AS1 inhibited in vivo tumorigenesis

Sh-SH3PXD2A-AS1-transfected DLD-1 cells or empty-vector-transfected DLD-1 cells were injected into BALB/c nude mice with 4 weeks old. Measurement of tumors for up to 24 days after inoculation showed that the sizes of tumors derived from sh-SH3PXD2AAS1-transfected DLD-1 cells were obviously smaller than those derived from emptyvector-transfected DLD-1 cells (Fig. 5A). Furthermore, the expression of SH3PXD2A-AS1 was significantly decreased in tumors formed from sh-SH3PXD2A-AS1-transfected DLD1 cells (Fig. 5B). Additionally, tumor volumes were measured every 4 days in the shSH3PXD2A-AS1 and empty vector groups (Fig. 5C), and tumor weight was markedly lower in the sh-SH3PXD2A-AS1 group than in the empty-vector group (Fig. 5D). Consistently, immunohistochemical (IHC) analysis showed that tumors formed in the sh-SH3PXD2AAS1 group exhibited lower ki-67 expression than those in the empty vector group (Fig. 5E). Thus, these findings provided insights into the effects of SH3PXD2A-AS1 downregulation on tumorigenesis in vivo. 


\section{Cellular Physiology Cell Physiol Biochem 2018;46:2197-2214 \begin{tabular}{ll|l}
\cline { 2 - 2 } aOI: 10.1159/000489589 & $\begin{array}{l}\text { ( ) } 2018 \text { The Author(s). Published by S. Karger AG, Basel } \\
\text { www.karger.com/cpb }\end{array}$ \\
\hline
\end{tabular} \\ Ma et al.: The Oncogenic Role of SH3PXD2A-AS1 in CRC Progression}

Fig. 8. SH3PXD2AAS1 exhibited an inverse correlation with expression of P57 and KLF2, which were anti-oncogenes in CRC progression. A. qPCR analysis was used to examine P57 and KLF2 expression levels in DLD-1 cells treated with pcDNAP57 or pcDNA-KLF2. B. The protein levels of P57 and KLF2 were tested in DLD-1 cells transfected with pcDNA-P57 or pcDNA-KLF2 using western blot experiments. C. Overexpression of P57 or KLF2 could inhibit cell viability in CRC. D. DLD-1 cells transfected with empty vector, pcDNA-P57, or pcDNA-KLF2 were analyzed by flow cytometry. E-F. MTT and colony formation experiments were used
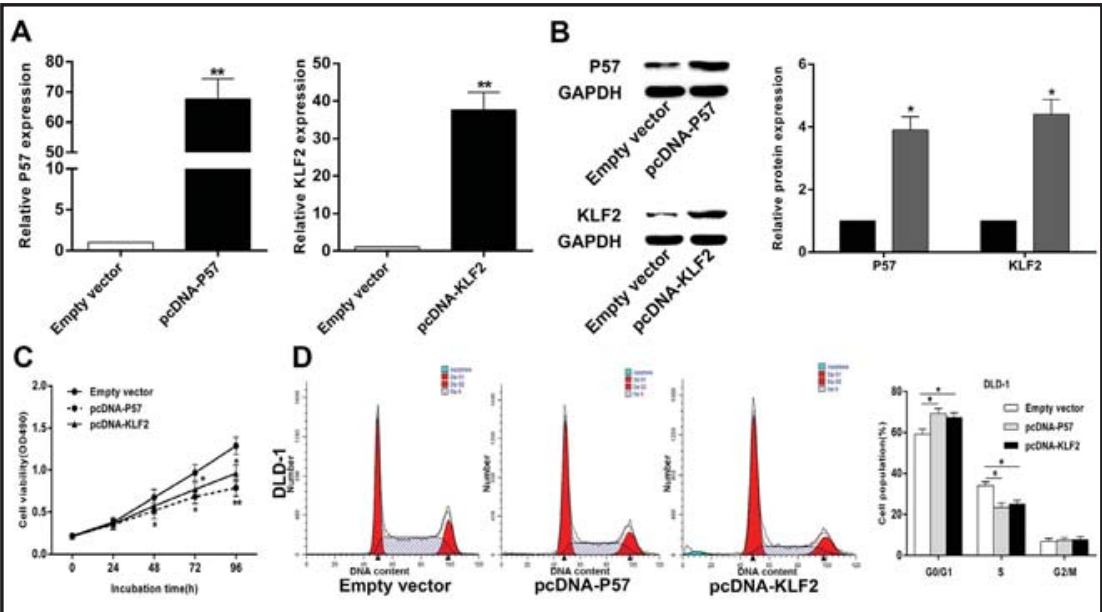

IE
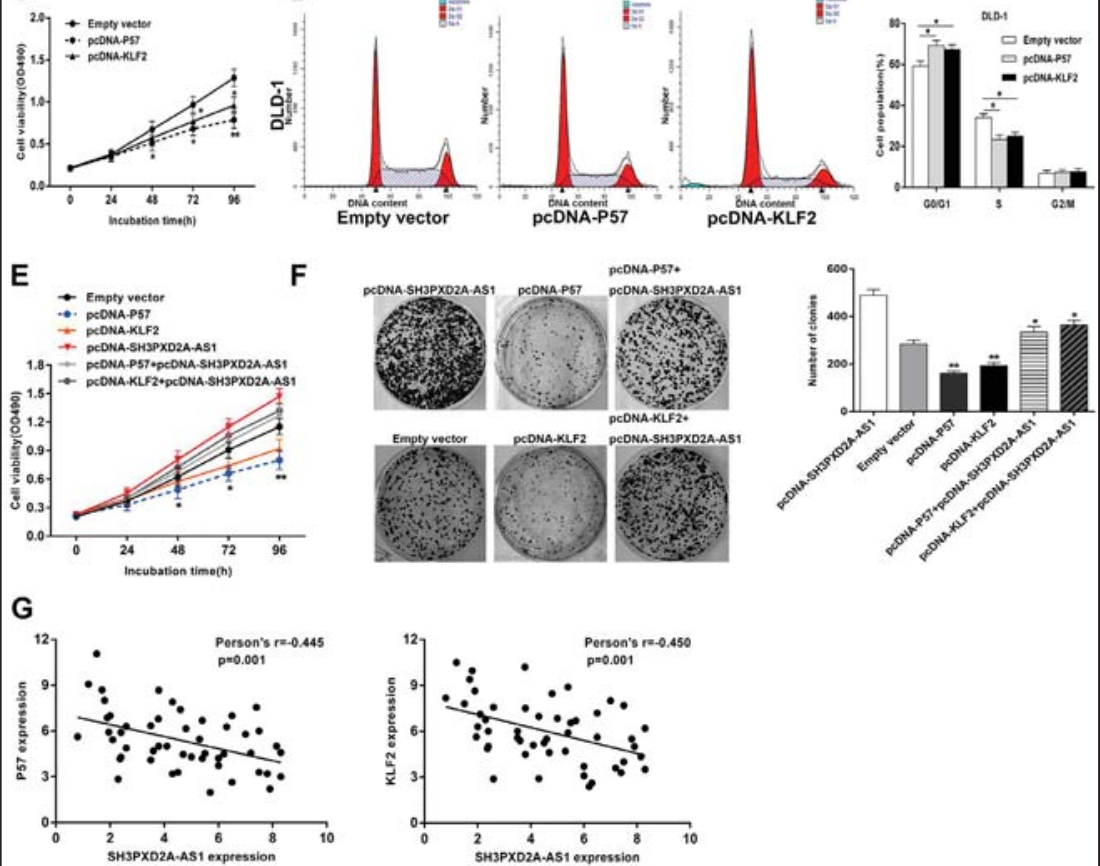

G
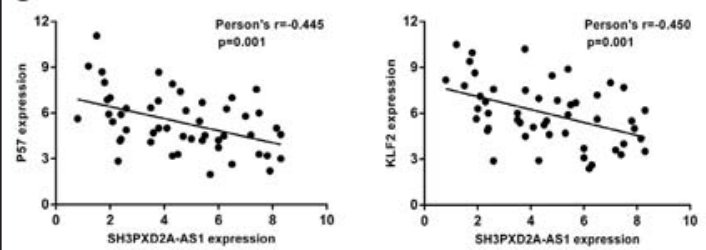

to determine the cell viability for pcDNA-SH3PXD2A-AS1 and pcDNA-P57 or pcDNA-KLF2 cotransfected DLD-1 cells. G. The expression levels of P57 and KLF2 were examined in 50 pairs CRC tissues using qRT-PCR, and an inverse correlation was found between SH3PXD2A-AS1 and P57 or KLF2 in CRC. Values are shown as the mean \pm s.d in three independent experiments. ${ }^{*} \mathrm{P}<0.05$, ${ }^{* *} \mathrm{P}<0.01$.

\section{SH3PXD2A-AS1 suppressed P57 and KLF2 expression through interaction with EZH2}

Recent studies have suggested that lncRNAs are required for epigenetic regulation of target genes through binding with PRC2, thus contributing to cancer progression [30, 35, 36]. EZH2 and SUZ12, as two core components of PRC2 complex, have been shown to be involved in cancer progression [37-39]. In this study, we examined EZH2 expression in 50 CRC tissue samples and adjacent non-tumor tissue samples. Compared with adjacent nontumor tissue samples, EZH2 was obviously upregulated in CRC tissue samples (Fig. 6A). Furthermore, EZH2 was markedly overexpressed in SW480 and DLD-1 cells compared with that in HCoEpiC cells (Fig. 6B). Additionally, EZH2 siRNAs were used to knock down EZH2 expression in SW480 and DLD-1 cells (Fig. 6C).

The regulatory mechanisms of IncRNAs primarily depend on the distribution of IncRNAs in the cell. Thus, we next determined the distribution of SH3PXD2A-AS1 in SW480 and DLD1 cells. Our findings showed that SH3PXD2A-AS1 levels were higher in the nucleus than in the cytoplasm (Fig. 6D), implying that SH3PXD2A-AS1 may regulate the expression of target genes at transcriptional levels. In situ hybridization (ISH) assays using CRC tissue samples and non-tumor samples further demonstrated the distribution and localization of SH3PXD2AAS1 (Fig. 10B). To further explore the mechanism of SH3PXD2A-AS1 in CRC progression, 


\section{Cellular Physiology \\ Cell Physiol Biochem 2018;46:2197-2214 and Biochemistry

RNA immunoprecipitation (RIP) assays were performed to detect potential binding proteins that may bind to SH3PXD2AAS1 (Fig. 6E). Endogenous SH3PXD2A-AS1 was obviously enriched in anti-EZH2 RIP fraction. Furthermore, the data showed that endogenous SH3PXD2A-AS1 was also enriched in antiSUZ12 RIP fraction. These data suggested that SH3PXD2A-AS1 interacted most strongly with EZH2.

Cyclin-dependent protein kinase inhibitors (CKIs), which have indispensable roles in cell cycle control, can also influence the development and progression of cancer [40-42]. Because
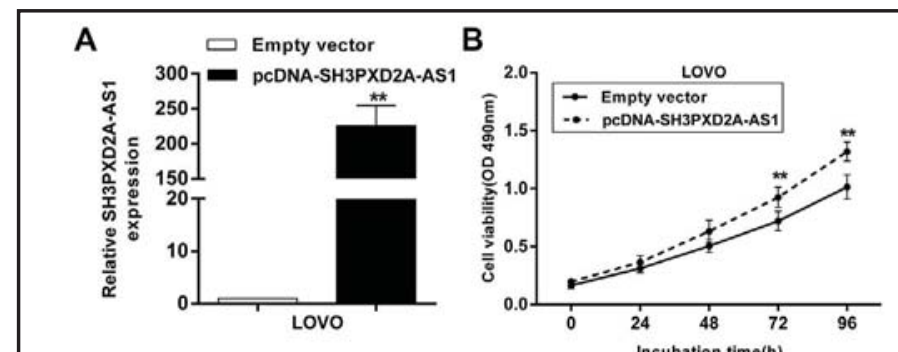

C
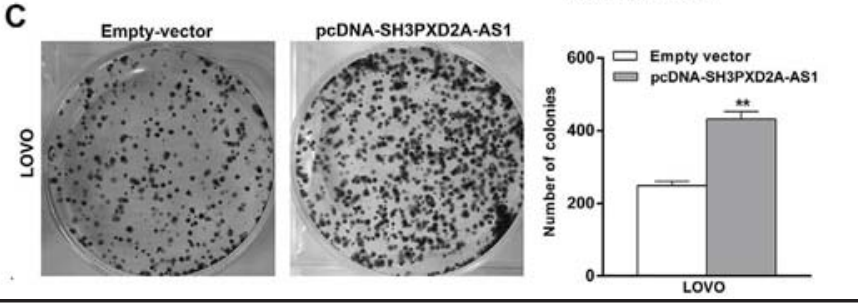

Fig. 9. The effects of SH3PXD2A-AS1 overexpression on CRC proliferation. A. qRT-PCR assays were performed to examine SH3PXD2AAS1 expression in LOVO cells transfected with pcDNA-SH3PXD2A-AS1. $\mathrm{B}-\mathrm{C}$. MTT and colony-formation assays were used to assess the role of SH3PXD2A-AS1 upregulation in CRC proliferation. Values are shown as the mean \pm s.d in three independent experiments. ${ }^{*} \mathrm{P}<0.05$, ${ }^{* *} \mathrm{P}<0.01$. of function of SH3PXD2AAS1 in modulating the cell cycle in CRC cells, we next examined the alterations of CKIs family members (including P15, P16, P21, P27, P57) in SW480 and DLD-1 cells with SH3PXD2A-AS1 knockdown. Kruppellike factor 2 (KLF2) and phosphatase and tensin homolog deleted from chromosome 10 (PTEN), as important tumor suppressors in many malignancies, have been identified to be involved in cell cycle and apoptosis [43-46]. Thus, we also detected the expression of KLF2 and PTEN in SW480 and DLD-1 cells with SH3PXD2A-AS1 knockdown. The data showed that P57 and KLF2 were remarkably upregulated in SW480 and DLD-1 cells with SH3PXD2A-AS1 knockdown at both mRNA level and protein level, compared with respective controls (Fig. 7A7B). Then, qRT-PCR assays showed that both P57 and KLF2 were significantly upregulated in EZH2-depleted SW480 and DLD-1 cells compared with negative controls (Fig. 7C). Thus, we concluded that P57 and KLF2 may be novel target genes of SH3PXD2A-AS1 in CRC. Chromatin immunoprecipitation (CHIP) assays were performed to further validate our hypothesis that SH3PXD2A-AS1 could mediate suppression of P57 and KLF2 through interaction with EZH2 in CRC. As shown in Fig. 7D, SH3PXD2A-AS1 downregulation decreased the bindings between EZH2 and promoter regions of P57 and KLF2 in SH3PXD2A-AS1-depleted SW480 and DLD-1 cells, relative to respective control cells. Taken together, these results showed that SH3PXD2A-AS1 could recruit EZH2 to promoter regions of P57 and KLF2 to silence P57 and KLF2 expression, thereby mediating CRC cells progression.

\section{Tumor-suppressive function of P57 and KLF2 in CRC}

P57 is a crucial component of CKIs family, which also includes P15, P16, P21, and P27 [47]. Our previous studies investigated the expression patterns of P57 in CRC tissues, and highlighted P57 as an important anti-oncogene in CRC progression [47, 48]. We also reported that IncRNA HOXA-AS2 mediated CRC proliferation partly through inhibiting P21 and KLF2 expression [30]. In addition, the effects of P15 and P16 on CRC progression have been studied previously [49-51].

In this study, we explored the role of P57 in CRC, with a special focus on determining the effects of P57 and KLF2 overexpression on CRC proliferation and cell cycle. P57 and KLF2 were obviously upregulated in DLD-1 cells transfected with pcDNA-P57 or pcDNA- 


\section{Cellular Physiology Cell Physiol Biochem 2018:46:2197-2214

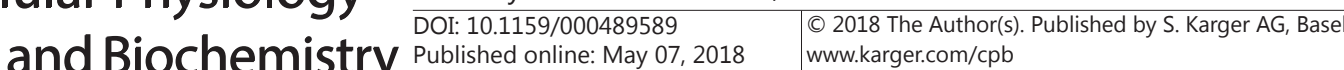

Fig. 10. SH3PXD2A-AS1 promotes CRC cells migration and invasion and its expression levels were examined in CRC tissues and matched non-tumor tissues using ISH assays. A. Transwell assays revealed that SH3PXD2A-AS1 knockdown inhibits colorectal cancer cell migration and invasion. Values are shown as the mean \pm s.d in three independent experiments. ${ }^{*} \mathrm{P}<0.05,{ }^{* *} \mathrm{P}<0.01$. B. Representative images of SH3PXD2A-AS1 expression in nontumor tissues and CRC tissues by ISH assays.

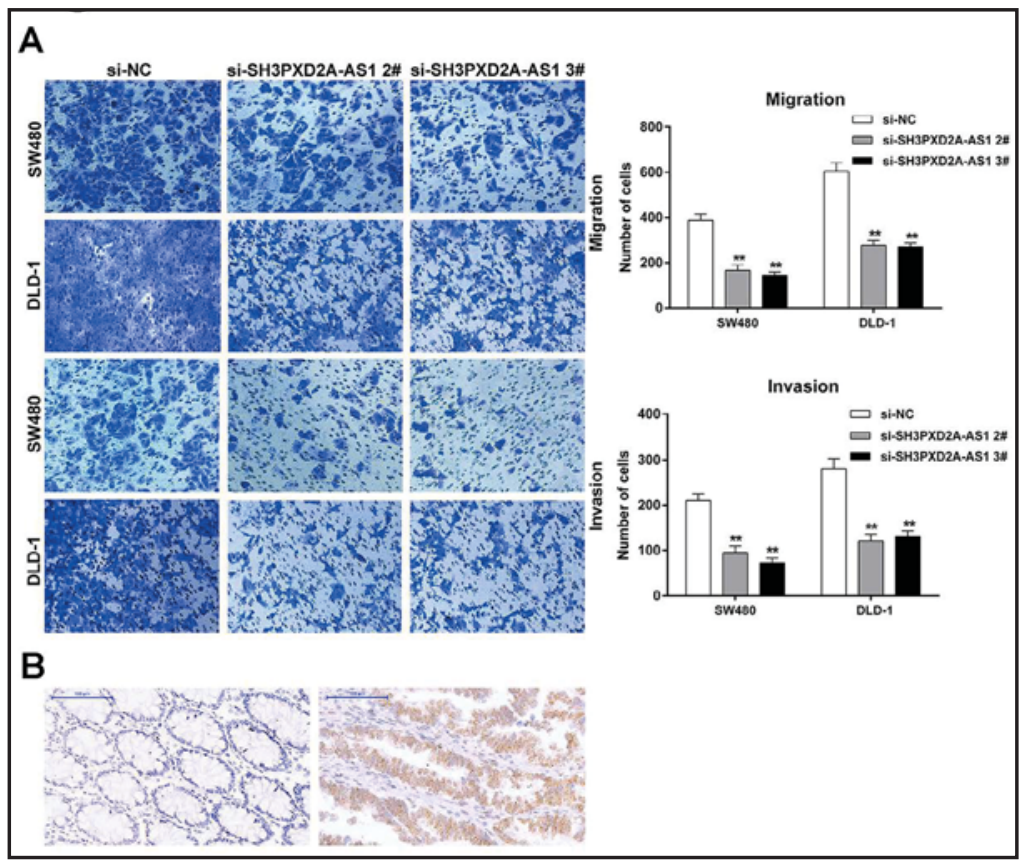

Fig. 11. The transfection efficiencies of shRNAs against SH3PXD2A-AS1 and EZH2 in CRC cell lines. A. qRT-PCR assays were performed to examine SH3PXD2A-AS1 expression levels in CRC cells lines transfected with SH3PXD2A-AS1 shRNAs. B. qRT-PCR assays were performed to examine EZH2 expression levels in CRC cells lines transfected with EZH2 shRNAs. C. MTT assays were used to determine the cell viability for sh-EZH2 and pcDNA P57 or pcDNA KLF2 cotransfected DLD-1 cells. Values are shown as the mean \pm s.d in three independent experiments. ${ }^{*} \mathrm{P}<0.05,{ }^{* *} \mathrm{P}<0.01$.
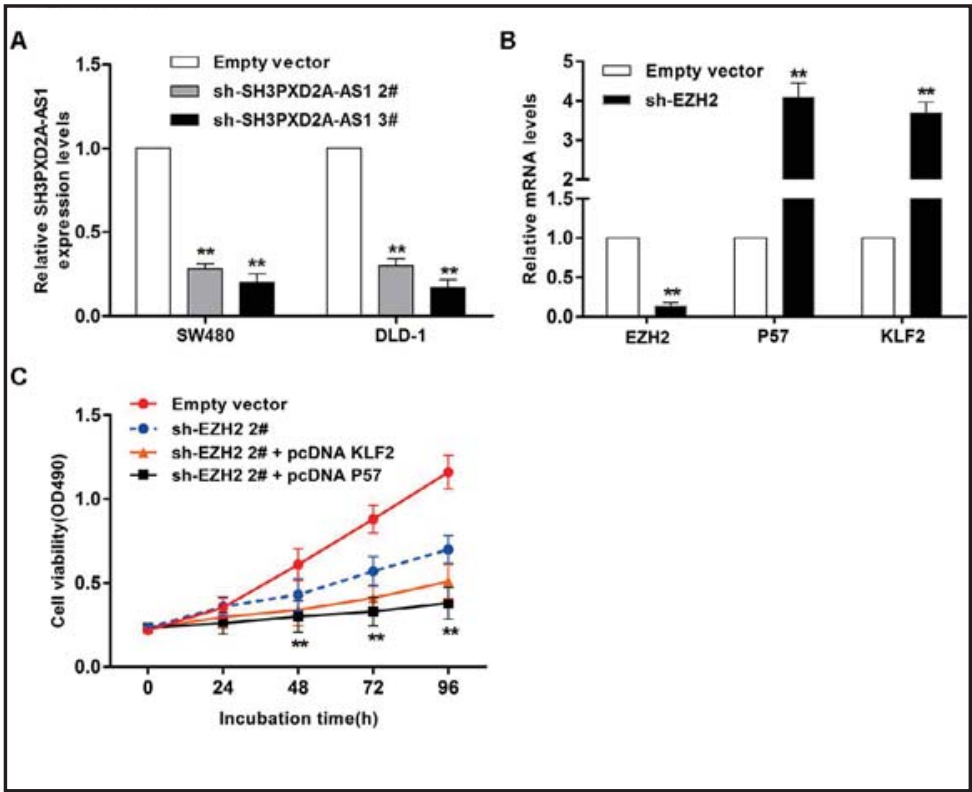

KLF2 at both mRNA and protein levels, compared with respective control group (Fig. 8A8B). Moreover, overexpression of P57 or KLF2 could inhibit cell viability in CRC (Fig. 8C). Additionally, flow cytometry assays showed that overexpression of P57 or KLF2 in DLD1 cells resulted in G1/G0 phase arrest (Fig. 8D). Thus, we concluded that P57 and KLF2 exerted tumor-suppressive functions in CRC.

The involvement of P57 and KLF2 in SH3PXD2A-AS1-mediated pro-oncogenic functions in CRC

Next, we conducted rescue assays to detect whether P57 and KLF2 were involved in SH3PXD2A-AS1-induced promotion of CRC proliferation. DLD-1 cells were cotransfected with pcDNA-SH3PXD2A-AS1 and pcDNA-P57 or pcDNA-KLF2. Notably, MTT and colonyformation assays revealed that this cotransfection partially reversed the promotion of 


\section{Cellular Physiology Cell Physiol Biochem 2018;46:2197-2214

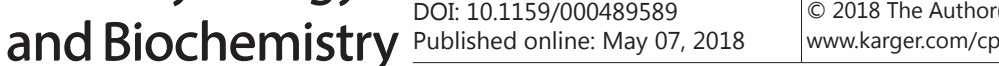 \\ Ma et al.: The Oncogenic Role of SH3PXD2A-AS1 in CRC Progression}

CRC proliferation mediated by pcDNA-SH3PXD2A-AS1 (Fig. 8E-8F). Moreover, MTT assays were also used to examine cell vaiblity in DLD-1 cells cotransfected with EZH2 shRNA and pcDNA-P57 or pcDNA-KLF2, thus indirectly revealing the effects of EZH2 on SH3PXD2AAS1-mediated suppression of P57 and KLF2 (Fig. 11C). Finally, we further determined that SH3PXD2A-AS1 could negatively modulate the expression of P57 and KLF2 in CRC tissues (Fig. 8G). These results demonstrated that SH3PXD2A-AS1-mediated oncogenic role is partly through suppressing P57 and KLF2 in CRC.

\section{Discussion}

Dysregulation of IncRNAs has been identified to be correlated with the occurrence and progression of many malignancies, including CRC [52-54]. Current progress in RNA sequencing techniques has facilitated the discovery of these critical molecules associated with carcinogenesis $[55,56]$. In this study, we analyzed the publicly available data from The Cancer Genome Atlas (TCGA) and Gene Expression Omnibus (GEO) datasets, and screened SH3PXD2A-AS1 as a novel IncRNA involved in CRC progression. Our results showed that SH3PXD2A-AS1 was markedly upregulated in CRC tissue samples and that SH3PXD2A-AS1 overexpression was associated with tumor size, TNM stage, and lymph node metastasis in patients with CRC. Additionally, SH3PXD2A-AS1 downregulation caused G1/G0 phase arrest, impaired CRC cell proliferation capacity, and promoted apoptosis, whereas overexpression of SH3PXD2A-AS1 had the opposite effects. Thus, our findings revealed important roles of SH3PXD2A-AS1 in cell proliferation and cell cycle regulation in CRC.

The regulatory mechanism of IncRNAs depends primarily on the distribution of lncRNAs in cell. We found that SH3PXD2A-AS1 exhibited higher distribution in nucleus in CRC cell lines, suggesting that SH3PXD2A-AS1 may regulate the expression of target genes at transcriptional levels. Indeed, emerging evidence has demonstrated that IncRNAs can modulate the expression of target genes through binding with PRC2 complex, which affects epigenetic repression of target genes. For example, IncRNA PVT1 could bind with EZH2 to epigenetically silence LATS2 expression, thus contributing to non-small cell lung cancer (NSCLC) proliferation [57]. In our previous study, we also reported that lncRNA SNHG15 could interact with EZH2 in pancreatic cancer [58]. Here, we performed RIP experiments, and found that endogenous SH3PXD2A-AS1 exhibited significant enrichment in the antiEZH2 RIP fraction in SW480 and DLD-1 cells. Moreover, SH3PXD2A-AS1 could also interact with SUZ12 in SW480 and DLD-1 cell.

CKIs have been found to affect cell cycle progression and cell apoptosis in multiple cancers [42]. KLF2 and PTEN, critical tumor suppressors, also have indispensable roles in regulating cell cycle and apoptosis [43, 44, 59]. Notably, our findings showed that P57 and KLF2 were markedly upregulated in SH3PXD2A-AS1-depleted CRC cells at both the mRNA and protein levels. Moreover, P57 and KLF2 were also upregulated in EZH2-depleted CRC cell lines, suggesting that P57 and KLF2 may function as novel downstream targets of SH3PXD2AAS1 in CRC. Thus, we hypothesized that SH3PXD2A-AS1 could epigenetically suppress P57 and KLF2 through interaction with EZH2 in CRC. Furthermore, knockdown of SH3PXD2AAS1 was found to impair EZH2 binding capacity to the promoter regions of P57 and KLF2 in CRC cells, confirming that P57 and KLF2 are SH3PXD2A-AS1/EZH2-mediated target genes.

Our previous studies have highlighted P21 and P57 as important anti-oncogenes in CRC progression $[47,48]$. P15 and P16 have also been identified as tumor-suppressive proteins in CRC $[49,51]$. In this study, we reported that overexpression of P57 and KLF2 can inhibit proliferative ability of CRC cells, and cause G1/G0 phase arrest. We also found that SH3PXD2A-AS1 negatively regulated the expression of P57 and KLF2 in CRC tissues.

In summary, our findings showed thatSH3PXD2A-AS1 was remarkably upregulated inCRC tissues compared with matched non-tumor samples and its overexpression was significantly correlated with clinicopathological factors in patients with CRC. This expression pattern of SH3PXD2A-AS1 in CRC helps to fully understand the state of CRC patients. SH3PXD2A-AS1 


\section{Cellular Physiology Cell Physiol Biochem 2018;46:2197-2214 \begin{tabular}{ll|l}
\cline { 2 - 2 } aOI: 10.1159/000489589 & $\begin{array}{l}\text { ( ) } 2018 \text { The Author(s). Published by S. Karger AG, Basel } \\
\text { www.karger.com/cpb }\end{array}$ \\
\hline
\end{tabular} Ma et al.: The Oncogenic Role of SH3PXD2A-AS1 in CRC Progression}

may be a diagnostic biomarker and prognostic indicator for patients with CRC. In-vitro and in-vivo assays demonstrated that decreased SH3PXD2A-AS1 could inhibit cell proliferation, cause G1/G0 phase arrest, and increased apoptotic rates in CRC. Importantly, mechanistic experiments firstly revealed that SH3PXD2A-AS1 could epigenetically suppress P57 and KLF2 expression through EZH2-mediated H3K27me3, thus contributing to CRC proliferation. Our findings provide important insights into CRC pathogenesis, and are expected to facilitate the development of approaches for early diagnosis and targeted therapy of CRC based on lncRNAs. Recent investigations have revealed that antisense transcripts can exert effects via inducing their neighbouring protein-coding genes [60-62]. However, whether SH3PXD2AAS1 can modulate SH3PXD2A and other possible target genes is still unclear, and the underlying mechanisms have not yet been explored in this study. Therefore, more efforts should be devoted to elucidate the mechanisms involved in these processes.

\section{Acknowledgements}

This study was supported by Grant No.81772603 from the National Natural Science Foundation of China.

\section{Disclosure Statement}

The authors declare to have no conflict of interests.

\section{References}

1 Siegel RL, Miller KD, Jemal A: Cancer Statistics, 2017. CA Cancer J Clin 2017;67:7-30.

-2 Siegel RL, Miller KD, Fedewa SA, Ahnen DJ, Meester R, Barzi A, Jemal A: Colorectal cancer statistics, 2017. CA Cancer J Clin 2017;67:177-193.

-3 Siegel R, Desantis C, Jemal A: Colorectal cancer statistics, 2014. CA Cancer J Clin 2014;64:104-117.

4 Correction: Long noncoding RNA GCASPC, a target of miR-17-3p, negatively regulates pyruvate Carboxylase-Dependent cell proliferation in gallbladder cancer. Cancer Res 2017;77:1503.

5 Malakar P, Shilo A, Mogilevsky A, Stein I, Pikarsky E, Nevo Y, Benyamini H, Elgavish S, Zong X, Prasanth KV, Karni R: Long noncoding RNA MALAT1 promotes hepatocellular carcinoma development by SRSF1 upregulation and mTOR activation. Cancer Res 2017;77:1155-1167.

6 Kong J, Sun W, Li C, Wan L, Wang S, Wu Y, Xu E, Zhang H, Lai M: Long non-coding RNA LINC01133 inhibits epithelial-mesenchymal transition and metastasis in colorectal cancer by interacting with SRSF6. Cancer Lett 2016;380:476-484.

7 Huang M, Hou J, Wang Y, Xie M, Wei C, Nie F, Wang Z, Sun M: Long noncoding RNA LINC00673 is activated by SP1 and exerts oncogenic properties by interacting with LSD1 and EZH2 in gastric cancer. Mol Ther 2017;25:1014-1026.

8 Wapinski O, Chang HY: Long noncoding RNAs and human disease. Trends Cell Biol 2011;21:354-361.

-9 Iyer MK, Niknafs YS, Malik R, Singhal U, Sahu A, Hosono Y, Barrette TR, Prensner JR, Evans JR, Zhao S, Poliakov A, Cao X, Dhanasekaran SM, Wu YM, Robinson DR, Beer DG, Feng FY, Iyer HK, Chinnaiyan AM: The landscape of long noncoding RNAs in the human transcriptome. Nat Genet 2015;47:199-208.

10 Mercer TR, Dinger ME, Mattick JS: Long non-coding RNAs: Insights into functions. Nat Rev Genet 2009;10:155-159.

11 Tian F, Xu J, Xue F, Guan E, Xu X: TINCR expression is associated with unfavorable prognosis in patients with hepatocellular carcinoma. Biosci Rep 2017

12 Shen B, Yuan Y, Zhang Y, Yu S, Peng W, Huang X, Feng J: Long non-coding RNA FBXL19-AS1 plays oncogenic role in colorectal cancer by sponging miR-203. Biochem Biophys Res Commun 2017;488:67-73.

13 Qi F, Liu X, Wu H, Yu X, Wei C, Huang X, Ji G, Nie F, Wang K: Long noncoding AGAP2-AS1 is activated by SP1 and promotes cell proliferation and invasion in gastric cancer. J Hematol Oncol 2017;10:48. 


\section{Cellular Physiology Cell Physiol Biochem 2018;46:2197-2214 \begin{tabular}{l|l} 
and Biochemistry Published onlIne: May 07, 2018 & $\begin{array}{l}\text { C) } 2018 \text { The Author(s). Published by S. Karger AG, Basel } \\
\text { www.karger.com/cpb }\end{array}$ \\
\hline
\end{tabular} \\ Ma et al.: The Oncogenic Role of SH3PXD2A-AS1 in CRC Progression}

14 Wen Q Liu Y, Lyu H, Xu X, Wu Q Liu N, Yin Q Li J, Sheng X: Long Noncoding RNA GAS5, Which Acts as a Tumor Suppressor via microRNA 21, Regulates Cisplatin Resistance Expression in Cervical Cancer. Int J Gynecol Cancer 2017;27:1096-1108.

-15 Xiang JF, Yin QF, Chen T, Zhang Y, Zhang XO, Wu Z, Zhang S, Wang HB, Ge J, Lu X, Yang L, Chen LL: Human colorectal cancer-specific CCAT1-L IncRNA regulates long-range chromatin interactions at the MYC locus. Cell Res 2014;24:513-531.

-16 Iguchi T, Uchi R, Nambara S, Saito T, Komatsu H, Hirata H, Ueda M, Sakimura S, Takano Y, Kurashige J, Shinden Y, Eguchi H, Sugimachi K, Maehara Y, Mimori K: A long noncoding RNA, lncRNA-ATB, is involved in the progression and prognosis of colorectal cancer. Anticancer Res 2015;35:1385-1388.

17 Sun M, Nie F, Wang Y, Zhang Z, Hou J, He D, Xie M, Xu L, De W, Wang Z, Wang J: LncRNA HOXA11-AS promotes proliferation and invasion of gastric cancer by scaffolding the chromatin modification factors PRC2, LSD1, and DNMT1. Cancer Res 2016;76:6299-6310.

18 Li J, Lian Y, Yan C, Cai Z, Ding J, Ma Z, Peng P, Wang K: Long non-coding RNA FOXP4-AS1 is an unfavourable prognostic factor and regulates proliferation and apoptosis in colorectal cancer. Cell Prolif 2017;50

19 Holoch D, Margueron R: Mechanisms regulating PRC2 recruitment and enzymatic activity. Trends Biochem Sci 2017;42:531-542.

-20 Zhang EB, Yin DD, Sun M, Kong R, Liu XH, You LH, Han L, Xia R, Wang KM, Yang JS, De W, Shu YQ, Wang ZX: P53-regulated long non-coding RNA TUG1 affects cell proliferation in human non-small cell lung cancer, partly through epigenetically regulating HOXB7 expression. Cell Death Dis 2014;5:e1243.

21 Zhang E, Yin D, Han L, He X, Si X, Chen W, Xia R, Xu T, Gu D, De W, Guo R, Xu Z, Chen J: E2F1-induced upregulation of long noncoding RNA LINC00668 predicts a poor prognosis of gastric cancer and promotes cell proliferation through epigenetically silencing of CKIs. Oncotarget 2016;7:23212-23226.

22 Kotake Y, Nakagawa T, Kitagawa K, Suzuki S, Liu N, Kitagawa M, Xiong Y: Long non-coding RNA ANRIL is required for the PRC2 recruitment to and silencing of p15(INK4B) tumor suppressor gene. Oncogene 2011;30:1956-1962.

23 Wang Y, Hou N, Cheng X, Zhang J, Tan X, Zhang C, Tang Y, Teng Y, Yang X: Ezh2 acts as a tumor suppressor in kras-driven lung adenocarcinoma. Int J Biol Sci 2017;13:652-659.

24 Qi W, Zhao K, Gu J, Huang Y, Wang Y, Zhang H, Zhang M, Zhang J, Yu Z, Li L, Teng L, Chuai S, Zhang C, Zhao M, Chan H, Chen Z, Fang D, Fei Q, Feng L, Feng L, Gao Y, Ge H, Ge X, Li G, Lingel A, Lin Y, Liu Y, Luo F, Shi M, Wang L, Wang Z, Yu Y, Zeng J, Zeng C, Zhang L, Zhang Q Zhou S, Oyang C, Atadja P, Li E: An allosteric PRC2 inhibitor targeting the H3K27me3 binding pocket of EED. Nat Chem Biol 2017;13:381-388.

25 Ma X, Wang J, Wang J, Ma CX, Gao X, Patriub V, Sklar JL: The JAZF1-SUZ12 fusion protein disrupts PRC2 complexes and impairs chromatin repression during human endometrial stromal tumorogenesis. Oncotarget 2017;8:4062-4078.

26 Wu Y, Zhang L, Zhang L, Wang Y, Li H, Ren X, Wei F, Yu W, Liu T, Wang X, Zhou X, Yu J, Hao X: Long noncoding RNA HOTAIR promotes tumor cell invasion and metastasis by recruiting EZH2 and repressing E-cadherin in oral squamous cell carcinoma. Int J Oncol 2015;46:2586-2594.

-27 Zhang K, Sun X, Zhou X, Han L, Chen L, Shi Z, Zhang A, Ye M, Wang Q, Liu C, Wei J, Ren Y, Yang J, Zhang J, Pu P, Li M, Kang C: Long non-coding RNA HOTAIR promotes glioblastoma cell cycle progression in an EZH2 dependent manner. Oncotarget 2015;6:537-546.

-28 Kogo R, Shimamura T, Mimori K, Kawahara K, Imoto S, Sudo T, Tanaka F, Shibata K, Suzuki A, Komune S, Miyano S, Mori M: Long noncoding RNA HOTAIR regulates polycomb-dependent chromatin modification and is associated with poor prognosis in colorectal cancers. Cancer Res 2011;71:6320-6326.

29 Ding J, Li J, Wang H, Tian Y, Xie M, He X, Ji H, Ma Z, Hui B, Wang K, Ji G: Long noncoding RNA CRNDE promotes colorectal cancer cell proliferation via epigenetically silencing DUSP5/CDKN1A expression. Cell Death Dis 2017;8:e2997.

-30 Ding J, Xie M, Lian Y, Zhu Y, Peng P, Wang J, Wang L, Wang K: Long noncoding RNA HOXA-AS2 represses P21 and KLF2 expression transcription by binding with EZH2, LSD1 in colorectal cancer. Oncogenesis 2017;6:e288.

-31 Jacob A, Linklater E, Bayless BA, Lyons T, Prekeris R: The role and regulation of Rab40b-Tks5 complex during invadopodia formation and cancer cell invasion. J Cell Sci 2016;129:4341-4353.

-32 Stylli SS, I ST, Kaye AH, Lock P: Prognostic significance of Tks5 expression in gliomas. J Clin Neurosci 2012;19:436-442. 


\section{Cellular Physiology Cell Physiol Biochem 2018;46:2197-2214 \begin{tabular}{c|l} 
DOI: 10.1159/000489589 & (0) 2018 The Author(s). Published by S. Karger AG, Basel \\
and Biochemistry
\end{tabular} \\ Ma et al.: The Oncogenic Role of SH3PXD2A-AS1 in CRC Progression}

-33 Cejudo-Martin P, Yuen A, Vlahovich N, Lock P, Courtneidge SA, Diaz B: Genetic disruption of the sh3pxd2a gene reveals an essential role in mouse development and the existence of a novel isoform of tks5. Plos One 2014;9:e107674.

34 Ke Y, Bao T, Zhou Q, Wang Y, Ge J, Fu B, Wu X, Tang H, Shi Z, Lei X, Zhang C, Tan Y, Chen H, Guo Z, Wang L: Discs large homolog 5 decreases formation and function of invadopodia in human hepatocellular carcinoma via Girdin and Tks5. Int J Cancer 2017;141:364-376.

-35 Liu YW, Sun M, Xia R, Zhang EB, Liu XH, Zhang ZH, Xu TP, De W, Liu BR, Wang ZX: LincHOTAIR epigenetically silences miR34a by binding to PRC2 to promote the epithelial-to-mesenchymal transition in human gastric cancer. Cell Death Dis 2015;6:e1802.

-36 Li JK, Chen C, Liu JY, Shi JZ, Liu SP, Liu B, Wu DS, Fang ZY, Bao Y, Jiang MM, Yuan JH, Qu L, Wang LH: Long noncoding RNA MRCCAT1 promotes metastasis of clear cell renal cell carcinoma via inhibiting NPR3 and activating p38-MAPK signaling. Mol Cancer 2017;16:111.

-37 Liu B, Pang B, Wang Q, Yang S, Gao T, Ding Q, Liu H, Yang Y, Fan H, Zhang R, Xin T, Xu G, Pang Q: EZH2 upregulation correlates with tumor invasiveness, proliferation, and angiogenesis in human pituitary adenomas. Hum Pathol 2017

-38 Hu H, Wang Y, Li Z, Zhu Y, Zhang W, Wang D, Lin T, Yang J, Wang Y, Cheng J: Overexpression of suppressor of zest 12 is associated with cervical node metastasis and unfavorable prognosis in tongue squamous cell carcinoma. Cancer Cell Int 2017;17:26.

-39 Liu H, Li W, Yu X, Gao F, Duan Z, Ma X, Tan S, Yuan Y, Liu L, Wang J, Zhou X, Yang Y: EZH2-mediated Puma gene repression regulates non-small cell lung cancer cell proliferation and cisplatin-induced apoptosis. Oncotarget 2016;7:56338-56354.

40 Qiu H, Liu F, Tao T, Zhang D, Liu X, Zhu G, Xu Z, Ni R, Shen A: Modification of p27 with O-linked $\mathrm{N}$-acetylglucosamine regulates cell proliferation in hepatocellular carcinoma. Mol Carcinog 2017;56:258271.

-41 Ji Q Hu H, Yang F, Yuan J, Yang Y, Jiang L, Qian Y, Jiang B, Zou Y, Wang Y, Shao C, Gong Y: CRL4B interacts with and coordinates the SIN3A-HDAC complex to repress CDKN1A and drive cell cycle progression. J Cell Sci 2014;127:4679-4691.

42 Lim S, Kaldis P: Cdks, cyclins and CKIs: Roles beyond cell cycle regulation. Development 2013;140:30793093.

-43 Wang HG, Cao B, Zhang LX, Song N, Li H, Zhao WZ, Li YS, Ma SM, Yin DJ: KLF2 inhibits cell growth via regulating HIF-1alpha/Notch-1 signal pathway in human colorectal cancer HCT116 cells. Oncol Rep 2017;38:584-590.

44 Jiang W, Xu X, Deng S, Luo J, Xu H, Wang C, Sun T, Lei G, Zhang F, Yang C, Zhou L, Wang F, Chen M: Methylation of kruppel-like factor 2 (KLF2) associates with its expression and non-small cell lung cancer progression. Am J Transl Res 2017;9:2024-2037.

-45 Mao QQ, Chen JJ, Dong L, Zhong L, Sun X: Kruppel-like factor 2 suppresses growth and invasion of gastric cancer cells in vitro and in vivo. J Biol Regul Homeost Agents 2016;30:703-712.

46 Choi BH, Xie S, Dai W: PTEN is a negative regulator of mitotic checkpoint complex during the cell cycle. Exp Hematol Oncol 2017;6:19.

47 Ma Z, Gu S, Song M, Yan C, Hui B, Ji H, Wang J, Zhang J, Wang K, Zhao Q: Long non-coding RNA SNHG17 is an unfavourable prognostic factor and promotes cell proliferation by epigenetically silencing P57 in colorectal cancer. Mol Biosyst 2017;13:2350-2361.

48 Lian Y, Ding J, Zhang Z, Shi Y, Zhu Y, Li J, Peng P, Wang J, Fan Y, De W, Wang K: The long noncoding RNA HOXA transcript at the distal tip promotes colorectal cancer growth partially via silencing of p21 expression. Tumour Biol 2016;37:7431-7440.

49 Su J, Zhang E, Han L, Yin D, Liu Z, He X, Zhang Y, Lin F, Lin Q Mao P, Mao W, Shen D: Long noncoding RNA BLACAT1 indicates a poor prognosis of colorectal cancer and affects cell proliferation by epigenetically silencing of p15. Cell Death Dis 2017;8:e2665.

50 Abdel-Rahman WM, Nieminen TT, Shoman S, Eissa S, Peltomaki P: Loss of p15INK(4)b expression in colorectal cancer is linked to ethnic origin. Asian Pac J Cancer Prev 2014;15:2083-2087.

51 Al-Ahwal M, Gomaa W, Emam E, Qari Y, Buhmeida A, Radwi S, Al-Maghrabi B, Al-Qahtani M, Al-Maghrabi J: P16 protein is upregulated in a stepwise fashion in colorectal adenoma and colorectal carcinoma. Saudi J 


\section{Cellular Physiology Cell Physiol Biochem 2018;46:2197-2214 \begin{tabular}{ll|l|l|}
\hline DOI: 10.1159/000489589 2018 The Author(s). Published by S. Karger AG, Basel \\
\hline
\end{tabular} and Biochemistry Published online: May 01, 2018 www.karger.com/cpb \\ Ma et al.: The Oncogenic Role of SH3PXD2A-AS1 in CRC Progression}

Gastroenterol 2016;22:435-440.

-52 Tsai MC, Spitale RC, Chang HY: Long intergenic noncoding RNAs: New links in cancer progression. Cancer Res 2011;71:3-7.

53 Spizzo R, Almeida MI, Colombatti A, Calin GA: Long non-coding RNAs and cancer: A new frontier of translational research? Oncogene 2012;31:4577-4587.

54 Sun M, Nie FQ, Wang ZX, De W: Involvement of IncRNA dysregulation in gastric cancer. Histol Histopathol 2016;31:33-39.

55 Li J, Han L, Roebuck P, Diao L, Liu L, Yuan Y, Weinstein JN, Liang H: TANRIC: An interactive open platform to explore the function of IncRNAs in cancer. Cancer Res 2015;75:3728-3737.

-56 Liz J, Esteller M: LncRNAs and microRNAs with a role in cancer development. Biochim Biophys Acta 2016;1859:169-176.

57 Wan L, Sun M, Liu GJ, Wei CC, Zhang EB, Kong R, Xu TP, Huang MD, Wang ZX: Long noncoding RNA PVT1 promotes Non-Small cell lung cancer cell proliferation through epigenetically regulating LATS2 expression. Mol Cancer Ther 2016;15:1082-1094.

-58 Ma Z, Huang H, Wang J, Zhou Y, Pu F, Zhao Q Peng P, Hui B, Ji H, Wang K: Long non-coding RNA SNHG15 inhibits P15 and KLF2 expression to promote pancreatic cancer proliferation through EZH2-mediated H3K27me3. Oncotarget 2017;8:84153-84167.

59 Li A, Qiu M, Zhou H, Wang T, Guo W: PTEN, insulin resistance, and cancer. Curr Pharm Des 2017

60 Huang B, Song JH, Cheng Y, Abraham JM, Ibrahim S, Sun Z, Ke X, Meltzer SJ: Long non-coding antisense RNA KRT67-AS is activated in gastric cancers and supports cancer cell progression by increasing KRT7 expression. Oncogene 2016;35:4927-4936.

61 Liu C, Lin J: Long noncoding RNA ZEB1-AS1 acts as an oncogene in osteosarcoma by epigenetically activating ZEB1. Am J Transl Res 2016;8:4095-4105.

62 Yarmishyn AA, Batagov AO, Tan JZ, Sundaram GM, Sampath P, Kuznetsov VA, Kurochkin IV: HOXD-AS1 is a novel IncRNA encoded in HOXD cluster and a marker of neuroblastoma progression revealed via integrative analysis of noncoding transcriptome. Bmc Genomics 2014;15:S7. 